ÉGYPTE monde arabe

\section{Égypte/Monde arabe}

\author{
4 | 2007 \\ Figures de la santé en Égypte
}

\title{
Les guerres de la grippe aviaire en Égypte
}

Le traitement médiatique d'un virus émergent, janvier-mai 2006

\section{Matthieu Fintz et Sylla Thierno Youla}

\section{(2) OpenEdition}

\section{Journals}

Édition électronique

URL : https://journals.openedition.org/ema/1780

DOI : $10.4000 /$ ema. 1780

ISSN : 2090-7273

Éditeur

CEDEJ - Centre d'études et de documentation économiques juridiques et sociales

Édition imprimée

Date de publication : 31 décembre 2007

Pagination : 269-302

ISBN : 2-6905838-43-4

ISSN : 1110-5097

Référence électronique

Matthieu Fintz et Sylla Thierno Youla, «Les guerres de la grippe aviaire en Égypte », Égypte/Monde arabe [En ligne], 4 | 2007, mis en ligne le 31 décembre 2008, consulté le 07 juillet 2022. URL : http:// journals.openedition.org/ema/1780 ; DOI : https://doi.org/10.4000/ema.1780 


\title{
Matthieu Fintz \& Sylla Thierno Youla
}

\section{LES GUERRES DE LA GRIPPE AVIAIRE}

\author{
LE TRAITEMENT MÉDIATIQUE D’UN VIRUS ÉMERGENT, \\ JANVIER-MAI 2006
}

\begin{abstract}
E n 2005-2006, il est apparu aux yeux de nombreux scientifiques, experts et médias du monde entier que la grippe aviaire était devenue un candidat potentiel idéal au titre de pandémie à venir (May, 2005 ; Derenne et Bricaire, 2005 ; Raoult, 2005) Depuis son apparition en 1997 à Hong Kong et sa réactivation dans la région en 2003-2004, le virus H5N1 avait en effet franchi les frontières de ses niches asiatiques pour s'implanter en Europe, au Moyen Orient et en Afrique subsaharienne. Les cas $d^{\prime}$ infection humaine s'accroissaient, faisant craindre une mutation du virus autorisant sa transmission d'homme à homme. L'épizootie prit alors les contours d'une pandémie émergente.
\end{abstract}

Le 17 février 2006, le gouvernement égyptien lance à son tour une alerte à la grippe aviaire. La liste publiée du nombre de gouvernorats touchés s'accroît de jour en jour. Des mesures sont arrêtées, comme l'interdiction de la vente de volaille vivante, qui se traduit par la fermeture des boutiques de rue spécialisées dans la vente de volaille, l'abattage des poulets infectés dans les élevages et la destruction des élevages domestiques ou encore l'interdiction du transport de volailles entre les gouvernorats. Un mois plus tard, le premier décès dû au H5N1 est enregistré et le pays s'enlise dans ce que les journaux nomment désormais la " crise de la grippe aviaire ${ }^{1}$.

L'actualité donnée aux maladies infectieuses par les virus émergents ne cesse d'interroger les sciences biomédicales et sanitaires sur les propriétés émergentes acquises par des écosystèmes qui se modifient sous l'effet de l'action humaine. La capacité de ces virus à transgresser les frontières territoriales et politiques aussi bien que les barrières entre les espèces plaide en effet pour

1. En avril 2007, 14 personnes étaient décédées des suites de l'infection à H5N1 en Égypte sur un total de 34 cas. Six premiers décès ont eu lieu entre mars et mai 2006. Les décès ont réapparu au début du mois de novembre 2006. 
une attention scientifique accrue à la " globalisation » des maladies (i. e. les jeux d'échelle par lesquels une infection locale acquiert une dimension globale) et à la nécessaire coordination de la surveillance épidémiologique. Face à ce défi, les sciences sociales et historiques ont orienté leurs recherches vers des analyses multisituées permettant de retracer l'action de réseaux de recherche territorialisés ${ }^{2}$. En localisant ainsi la production des savoirs, elles rapportent l'émergence épistémique des maladies infectieuses, c'est-à-dire la prolifération d'inscriptions ${ }^{3}$ (Latour et Woolgar S., 1996, p. 42-43) et leur circulation (Latour, 2001), à une " écologie de la connaissance " ${ }^{4}$. L'analyse de la production locale des savoirs et de leur mise en circulation permet de comprendre l'importance prise par les virus émergents sur l'agenda de la santé publique internationale et les formes dans lesquelles ils sont saisis.

Loin d'être le seul apanage des scientifiques et experts, la compréhension des épidémies est aussi du ressort des médias, qui offrent à leurs lecteurs et téléspectateurs des récits, images et métaphores sur l'origine, la propagation et les moyens de se défaire du mal et de l'incertitude entourant son irruption. Au rebours d'une lecture qui ferait des news un genre de savoir vulgaire, on propose ici d'appréhender la presse écrite égyptienne comme une " niche » de l'écologie des savoirs sur la grippe aviaire. Le rôle des médias dans la mise en forme des épidémies est appelé à s'accroître à mesure de la globalisation de l'industrie culturelle elle-même ${ }^{5}$ pour laquelle ces nouveaux ennemis invisibles que sont les virus émergents sont des objets attrayants et rentables ${ }^{6}$.

2. Par exemple Lachenal G., 2005.

3. Au sens de produits de la transformation de la matière en écrit.

4. Par « écologie de la connaissance », I'historien de la médecine Charles Rosenberg entend l'étude « des relations entre le développement et la logique interne des idées sur le monde naturel et les formes sociales dans lesquelles cette connaissance est utilisée, validée et reproduite » dans Rosenberg, 1979. Pour Warwick Anderson, l'écologie de la connaissance consiste à dessiner les connections personnelles entre scientifiques et experts, à décrire un réseau international et à explorer les niches sociales et institutionnelles variées que ces scientifiques et experts occupent, Anderson, 2004, p. 41.

5. Sur les transformations actuelles des espaces médiatiques arabes et égyptien marqués par la naissance de journaux indépendants (au sens où ils ne dépendent ni des organismes publics de presse ni de partis politiques), ou encore par le développement des chaînes satellitaires des pays du Golfe et la multiplication des supports, cf. Mermier, 2003 ; Lamloum, 2004 ; Mellor, 2005 et Klaus 2006.

6. Ne perpétuant pas en cela de rupture radicale avec l'attrait déjà ancien de l'industrie culturelle pour les germes comme les bactéries ou les parasites, comme l'ont montré les études de Tomes, 2002. On peut se reporter à son ouvrage The gospel of Germs : Men, Women, and the Microbe in American life, 1998. Sur le lien entre professionnalisation du journalisme et mobilisation des sciences médicales, voir aussi Hansen 2004. Sur le traitement médiatique du virus Ebola, hautement symbolique de 
La collecte d'un vaste éventail de titres de la presse égyptienne, le dépouillement et le traitement du corpus d'articles et de caricatures recueillis montre que l'épizootie, puis l'épidémie, de grippe aviaire a représenté pour ces journaux un terrain d'élection à partir duquel ils se sont engouffrés dans une "politique de signification» (Hall, 1982). Ce travail médiatique sur les catégories utilisées pour observer la progression de l'épizootie, louer ou défier l'action gouvernementale, ou encore décrire les comportements des citoyens a contribué à mettre en forme le contexte de la lutte contre la grippe aviaire en Égypte. En d'autres termes, il a produit des cadres de perception et $d^{\prime}$ action. Les manières dont la presse a encadré l'arrivée de la grippe aviaire en Égypte et les dispositifs d'action publique constituent l'objet de cette recherche ${ }^{8}$.

La notion de cadrage (framing) fait référence au travail continu de mise en forme du contexte d'action auquel se livrent les multiples acteurs aux prises avec un problème public (Benford et Snow, 2000; Cefaï et Trom, 2001). Les cadres de l'action collective sont des « assemblages de croyances et significations qui inspirent et légitiment les activités et les campagnes d'une organisation de mouvement social » (Benford et Snow, 2000, p. 614), que celle-ci soit l'État, les médias ou des coalitions. L'historien de la médecine Charles Rosenberg a également eu recours à la notion de " cadrage » pour désigner "la fabrication [fashioning] des schèmes explicatifs et classificatoires »(Rosenberg, 1992, p. 307) au cours de laquelle une maladie particulière est perçue, nommée et prise en charge. Malgré leurs différences, ces deux approches supposent que les cadres sont orientés vers l'action

la catégorie de virus émergents, cf. Ungar, 1998. Sur le genre littéraire des killer virus novels, Dougherty, 2001. On doit aussi mentionner la croissance exponentielle du nombre de films ou de séries mettant un virus au centre de l'intrigue.

7. De janvier à mai 2006, nous avons collecté de manière la plus systématique possible les journaux suivants que nous regroupons selon un découpage grossier, mais utile : dans les titres gouvernementaux, les quotidiens Al-Ahrâm, Al-Jumuhûriya, AlAkhbâr, Rûz al-Yûsif ont été systématiquement dépouillés de même que les hebdomadaires Uktûbar, al-Musawwar et Rûz al-Yûsif Hebdo ; dans la presse partisane, Al-Wafd, Al-Ahâlî, Al-'Arabî, Al-Karâma, Afâq 'Arabiyya, Al-Ahrâr et dans les titres indépendants, Al-Dustûr, Al-Misrî al-Yawm, Al-'Usbû', Nahdat Misr.

8. Cette recherche a été entreprise dans le cadre d'une bourse de recherche postdoctorale du ministère des Affaires Étrangères français octroyée à l'un des auteurs (M. F.) pour un projet sur "Industrialisation des sciences biomédicales et intensification agricole en Égypte. La politique des virus émergents», 2005-2007 au Cedej. Le second auteur (S. T. Y.) est étudiant en master de lettres à I'Université du Caire. Nous tenons particulièrement à remercier pour leurs conseils et remarques Tewfik Aclimandos, Françoise Clément, Chaymaa Hassabo, Enrique Klaus et Jean-Gabriel Leturcq, Anne Marie Moulin et Saadia Radi. 
et qu'ils sont négociés collectivement à travers des processus discursifs et interactifs.

La production de métaphores est un aspect de l'activité de cadrage des épidémies (Sontag, 1977 ; Sontag, 1988 ; Gilman, 1988). Repérer les métaphores dans ces contextes revient à

comprendre comment [elles] s'entrecroisent avec d'autres séries de métaphores, comment elles peuvent créer un terrain commun entre les discours et comment elles fonctionnent dans l'interaction complexe de la science, des médias et de la politique. [...] Comment de telles métaphores sont [-elles] rendues plausibles et acceptables dans des situations sociopolitiques particulières. (Larson, Nerlich et Wallis, 2005 ${ }^{9}$ )

Ici, il s'agit de montrer comment le cadrage médiatique de la grippe aviaire nous renseigne non seulement sur les manières dont les médias ont fabriqué des visions de la lutte contre l'épidémie, ou encore sur ce que la grippe aviaire a permis de figurer métaphoriquement, mais aussi sur la (re)production d'un régime politique reposant sur la loi de l'état d'urgence depuis deux décades et pour lequel la «crise», la «catastrophe » et I' « état d'urgence » sont des catégories pertinentes et quotidiennes d'énonciation du politique ${ }^{10}$. Au-delà de la présentation d'événements permettant de comprendre le déroulement de cette crise sanitaire, l'étude de la « niche » médiatique égyptienne est donc susceptible de nous aider à comprendre les liens entre les virus émergents et les guerres contemporaines contre le terrorisme, entre la santé publique et I'agenda sécuritaire à partir du cas égyptien ${ }^{11}$. Tout se passe en effet comme si à la menace d'une guerre totale proche, traduisant un " choc des civilisations » (Huntington, 1996), répondait la peur d'une pandémie à venir («the coming plague », Garrett, 1994 ; DaSilva et laccarino, 1999). Cet ajustement de la santé publique à un agenda sécuritaire encadrerait, du même coup, les manières d'envisager la lutte contre les maladies infectieuses émergentes comme une guerre dont le langage reste à décrire.

Une caractéristique importante de l'activité de cadrage est qu'elle est elle-même émergente, au sens où elle est non prédictible et qu'elle agrège ou supprime des éléments dans le cours des modifications de l'environnement informationnel. La résolution d'une incertitude sur la cause de

9. Cette étude traite, entre autres, de l'usage de métaphores militaires dans la lutte contre la fièvre aphteuse en Grande Bretagne.

10. Nous tenterons de resituer les métaphores de la grippe aviaire non seulement dans le "système conceptuel " par rapport auquel elles prennent sens (cf. Lakoff et Johnson, 1985) mais aussi dans la dimension négociée de l'ordre social et politique. 11. De manière plus éditoriale qu'analytique, I'historienne Nancy Gallagher proposait en 1990 une telle "transitivité » entre les guerres militaires de l'Égypte au xx siècle et la lutte contre les épidémies de paludisme, choléra et fièvres récurrentes. 
l'épizootie et ses modes de propagation peut modifier l'image du mal. Le maintien de l'incertitude, au contraire, est propre à générer une profusion de récits et $d$ 'hypothèses. L'apparition de scandales lance l'enquête journalistique sur de nouveaux terrains et nouvelles métaphores. Un changement d'orientation donné par le gouvernement à son action modifie les termes de l'énonciation journalistique. Les acteurs (ministères, syndicats d'éleveurs et de commerçants, partis politiques, Parlement, médias) doivent constamment réaménager l'image qu'ils souhaitent donner de l'épidémie et de leur positionnement.

Dans cet article, nous nous emploierons uniquement à débrouiller les cadres de perception et d'action tels qu'ils ont été produits par la presse dans les premières semaines de la crise sanitaire. Ces manières de parler à propos de la grippe aviaire suggèrent la mise en place d'un réseau sémantique de la guerre qui n'est certes pas inventé ex nihilo lors de l'épizootie, mais qui n'en est pas moins actualisé, ré-assemblé et enrichi lorsque les médias écrits instituent la « crise » de la grippe aviaire.

L'émergence de la guerre dans le cadrage de la grippe aviaire sera appréhendée à partir de trois entrées. Une première entrée dans le registre de la guerre de la grippe aviaire consistera à réinscrire l'événement médiatique de la présence du virus en Égypte dans I'agenda journalistique égyptien. Celui-ci est déjà, à la mi-février 2006, fortement dominé par le langage de la guerre, en particulier dans le contexte de ce que certains ont nommé la « guerre des caricatures».

Dans un deuxième temps, nous reviendrons sur le moment où, à la stupéfaction générale, le gouvernement annonce, devant la progression rapide de l'infection, son plan de lutte axé sur l'abattage et la modernisation des normes de biosécurité. La guerre de la grippe aviaire devient une « guerre aux poulets ». La guerre de la grippe aviaire en Égypte peut alors être caractérisée par l'éclectisme des moyens de lutte où les réseaux informationnels les plus modernes de la surveillance épidémiologique côtoient la force intrusive de la surveillance policière. Nous montrons aussi comment, tout en voulant mấtriser l'image qu'il souhaite donner de son action, le gouvernement n'a pas pu empêcher la construction de récits alternatifs parvenant jusque dans les colonnes de la presse gouvernementale et laissant à penser que la guerre aux oiseaux était menée de façon " désordonnée ».

Dans un troisième moment, nous montrons comment le plan gouvernemental de modernisation du secteur avicole a débouché sur la mise en accusation des pratiques populaires d'élevage de volaille. La guerre de la grippe aviaire a, de ce point de vue, été aussi une croisade contre la tradition importante de l'élevage domestique, souvent situé hors d'atteinte des services vétérinaires. Et, dans cette lutte entre les forces œuvrant pour la concentration industrielle du secteur et les citoyens, l'ombre d'une " guerre aux pauvres » plane. 


\section{L'AGENDA MÉDIATIQUE DE LA PRESSE ÉCRITE ÉGYPTIENNE : D'UNE GUERRE L'AUTRE...}

L'épizootie de grippe aviaire n'est pas venue s'inscrire dans un vide médiatique. En février 2006, I'actualité égyptienne est notamment marquée par la controverse provoquée par les caricatures danoises et par la détérioration de la situation internationale au Moyen Orient. Cet agenda médiatique est fortement encadré par le spectre de la guerre. L'arrivée de la grippe aviaire, sur laquelle pèse une grande incertitude, va permettre aux médias de la presse écrite d'évoquer cette actualité à travers les images guerrières de l'oiseau décimé (ou abattu) ou celles de l'oiseau migrateur envahisseur.

De la « guerre » des caricatures à la « guerre aux poulets»

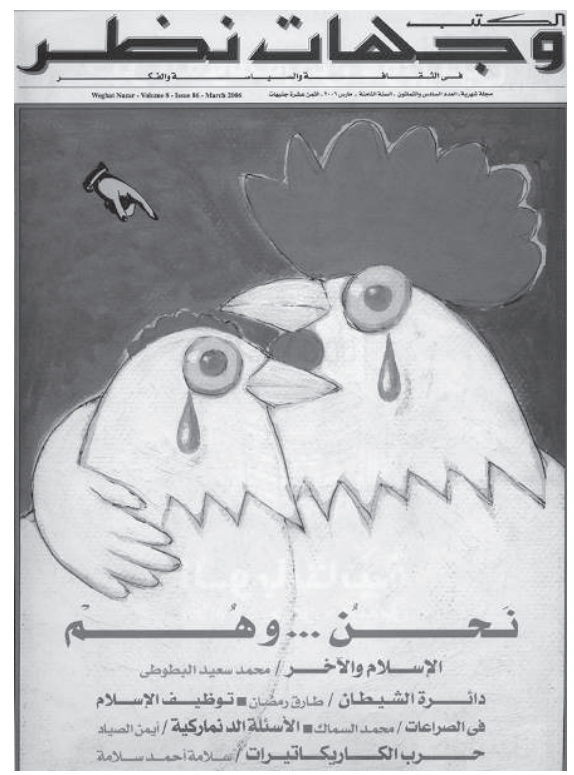

«Nous... et eux; L'Islam et l'Autre ; Les maisons de Satan ; Les usages de I'Islam dans les luttes; La question danoise ; La guerre des caricatures»

La grippe aviaire et la " guerre des caricatures"

Couverture du mensuel Wijhât Nazar, 86(8), 2006

On abat les poulets en Égypte ! On met les musulmans à l'index dans le monde! Deux évènements, I'arrivée de la grippe aviaire en Égypte, officiellement reconnue le 17 février 2006, et la controverse consécutive à la publication de caricatures du prophète Muhammad, publiées initialement le 30 septembre 2005 par le journal danois Jyllands Posten, se répondent I'un à l'autre dans ce dessin qui fait la couverture du numéro de mars de la revue mensuelle Wijhât Nazar. Entre les deux évènements, cette "Une » suggère une similitude de sort que partageraient musulmans et poulets. Les uns et les autres seraient soumis à un même régime : la guerre. "Guerre des caricatures » d'un côté, " guerre aux poulets » de l'autre. La représentation des musulmans en poulets pourrait bien aussi évoquer une autre idée, renforcée par le traitement médiatique en Égypte de l'invasion américaine de I'Afghanistan et de I'Irak, de la guerre globale contre le terrorisme ou encore de la seconde Intifada qui se prolonge et de l'occupation israélienne qui continue: on abattrait les musulmans comme des poulets! Dans ce dessin, la politique d'abattage des volailles, mesure préventive primordiale adoptée par 

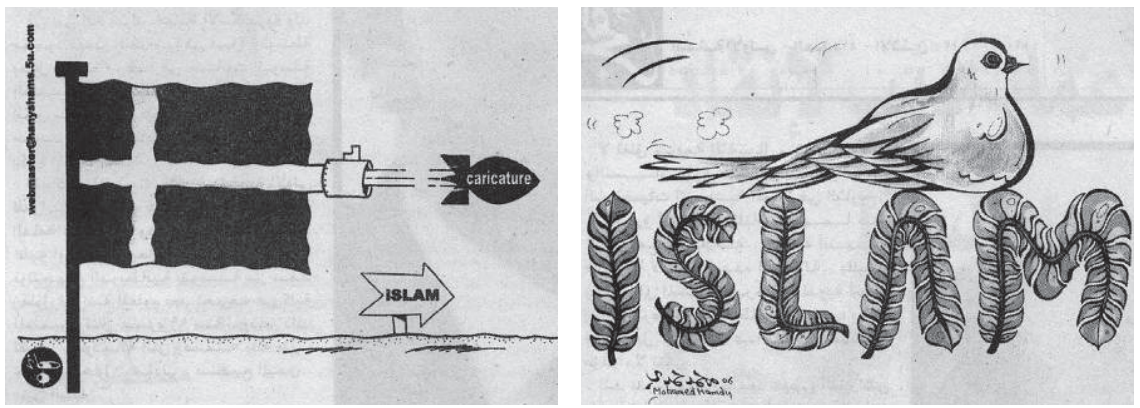

Al-Fajr, 13 mars 2006

Al-Fajr, 13 mars 2006

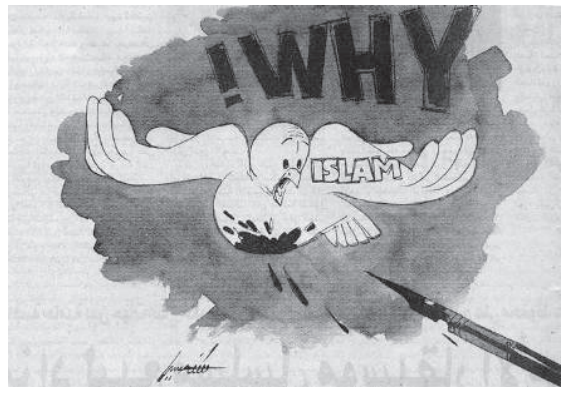

Al-Fajr, 13 mars 2006

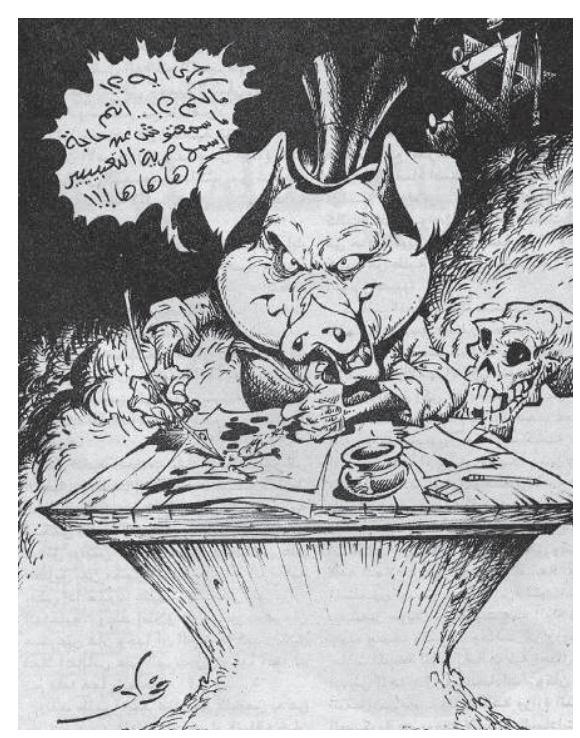

"Qu'est-ce qu'il y a ?! Qu'est-ce que vous avez ?! N'avez-vous pas entendu parler d'une chose qui s'appelle la liberté de la presse? Ah! Ah! Ah!»

Le porc américain, ses alliés juifs et la liberté de la presse Al-Fajr, 13 mars 2006

tous les gouvernements des pays atteints par le virus H5N1, se généralise symboliquement à l'humanité tout entière.

La "guerre » des caricatures, événement fortement médiatisé, constitue, au moment où la grippe aviaire devient un objet de traitement légitime pour les médias, un élément important de l'agenda médiatique. Cette liaison chronologique est aussi sémantique : la catégorie de guerre est imposée comme grille de lecture des deux évènements. La caricature serait un acte de guerre comme en témoigne ce drapeau danois transformé en canon tirant un obus en direction de I' "Islam ».

Nous reprenons ci-dessus quelques unes des caricatures publiées dans al-Fajr. Ce journal égyptien a été non seulement le premier organe de presse dans le monde arabe à publier quelques-uns des dessins danois dans son édition du 17 octobre 2006, mais aussi un des rares journaux égyptiens à se lancer dans une "contre-attaque » sur le même terrain dans son édition du 13 mars 2006, au moment où le «scandale » s'est mondialisé. Des appels au boycott des produits danois dans les pays arabes se multiplient et des 
attaques ciblées et cantonnées de certains symboles européens ont lieu en Iran, Syrie et Palestine.

Face aux « attaques » danoises, voire « occidentales », I'agressé (I' «Islam ») est représenté sous les traits de la colombe, symbole de paix, surprise dans son innocence par la plume des caricaturistes.

Mais I'innocence est définitivement perdue lorsqu'il s'agit, comme dans le dessin du " porc américain » d'assimiler la leçon de morale infligée par les "Occidentaux » aux opinions des pays majoritairement musulmans, à une énième perversion américano-sioniste. La guerre des significations est ici plus violemment affichée par la présence du porc, symbolisant l'ennemi américain derrière lequel une étoile de David, suspendue par des clous, impose sa présence latente et menaçante.

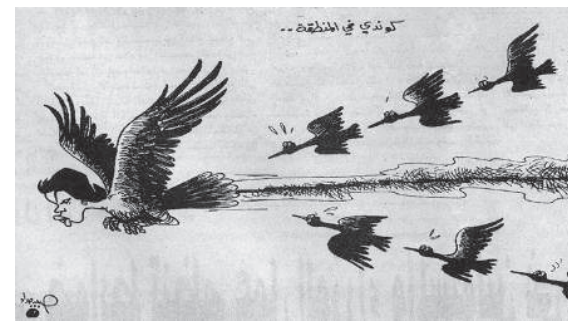

"Condie dans la région»

La grippe aviaire et le spectre de la menace américaine au Moyen Orient

Al-Fajr, 27 février 2006

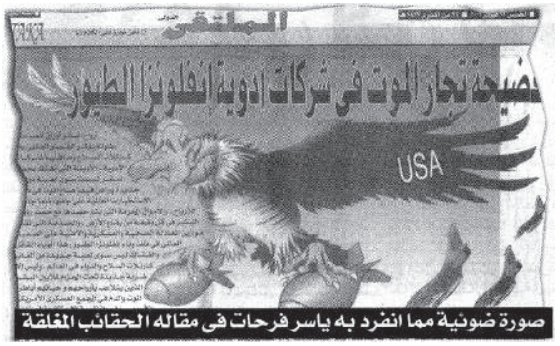

Le scandale des commerçants de la mort dans les sociétés de médicaments pour la grippe aviaire»

George W. Bush : le mal et le remède au mal Al-Multaqâ, 2 mars 2006
La colombe et l'oiseau prédateur : la grippe des processus de paix

La grippe aviaire et I'hypothèse de son arrivée en Égypte par les oiseaux migrateurs vont permettre d'illustrer la présence américaine au Moyen Orient sous les traits de l'invasion. Les projets américains pour la région sont dépeints à travers le prisme de I'oiseau migrateur, comme dans cette caricature de Condolezza Rice, suite à sa visite en Égypte dans la deuxième quinzaine de février 2006.

Plus fortement encore, la présence américaine est évoquée sous les traits de l'oiseau prédateur, survolant la région, armé de bombes, comme dans ce dessin représentant George W. Bush. La grippe aviaire a pu, dans les premières semaines du moins, être décrite sous la figure du complot ${ }^{12}$. Parmi les multiples récits du complot, une version soulignait le

12. Nous reviendrons ailleurs sur les récits du complot comme facteur $d^{\prime}$ institution de la crise de la grippe aviaire. Un journaliste égyptien a bien rendu compte de l'attrait des récits du complot de la grippe aviaire, Zalâqî (îhâb), "Les visions du complot », Al-Dustûr, $1^{\text {er }}$ mars 2006. 
subit intérêt de la communauté internationale pour cette épizootie et le fait que I'un des faucons de l'administration de la Défense américaine, Donald Rumsfeld, détenait des parts dans la société pharmaceutique productrice du Tamiflu, principal médicament utilisé pour contrôler les infections à H5N1. Selon cette vision, la grippe aviaire serait une bonne affaire pour les États-Unis en ce qu'elle leur permettrait d'asseoir leur domination sur le marché des médicaments.

Non plus dépeintes par la figure de l'oiseau migrateur, mais par celle de I'oiseau malade, certaines caricatures ont exprimé la précarité de la paix au Moyen Orient.

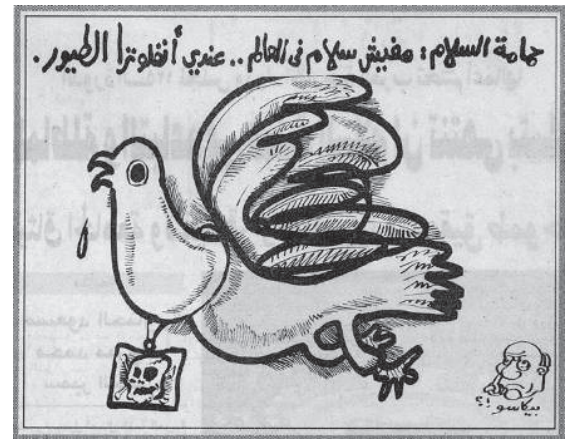

«La colombe : Il n'y a pas de paix dans le monde... j'ai la grippe aviaire » Al-Ahrâm, 5 mars 2006

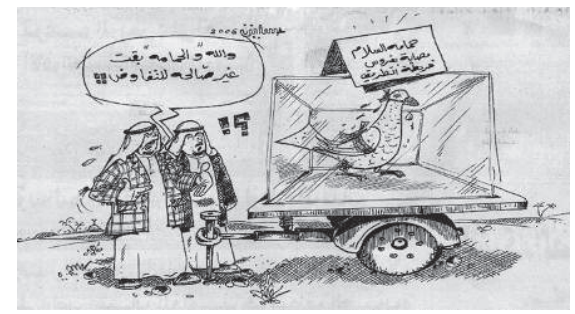

Sur l'écriteau : «Colombe infectée par le virus de la feuille de route» Les deux bédouins : "Par Dieu, la colombe est devenue impropre aux négociations » La " grippe » du processus de paix au Moyen Orient

Al-Ahâlî, 22 mars 2006

La colombe qui a la grippe aviaire exprime l'idée que le processus de paix entre Israéliens et Palestiniens, d'une part, et la « pacification » de l'Irak par les armées américaines, d'autre part, subissent de sérieux contre-feux. Lorsqu'au début du mois de mars, les attentats se multiplient en Irak, le journal Nahdat Misr évoque la " grippe de l'occupation et [le] spectre de la guerre civile » en Irak (Nahdat Misr, 2/3 mars 2006).

De son côté, I'hebdomadaire communiste Al-Ahâlî évoque le même processus d'enlisement, mais il le rapporte à la «feuille de route » tracée, le 30 avril 2003, par le quartette États-Unis, ONU, Russie et Union européenne, afin d'aboutir à la paix par étapes sur le principe de l'existence des deux États d'Israël et de Palestine. Cette feuille de route est ici le virus empêchant la paix d'advenir.

L'image des milliers de poulets égorgés à titre préventif dans les élevages égyptiens a pu être une troisième ressource pour exprimer la fin des espoirs de paix en Palestine. Dans ce dessin, plus besoin de virus ou d'oiseaux migrateurs, c'est la mobilisation de la politique d'abattage qui permet au dessinateur d'évoquer l'impasse des négociations de paix. Il suggère que des individus mal intentionnés réserveraient à la colombe (à la paix) le même sort qu'aux millions de poulets égyptiens égorgés à titre préventif. Il lie la politique d'abattage, privilégiée par le gouvernement égyptien, et le sabotage du processus de paix perpétré 


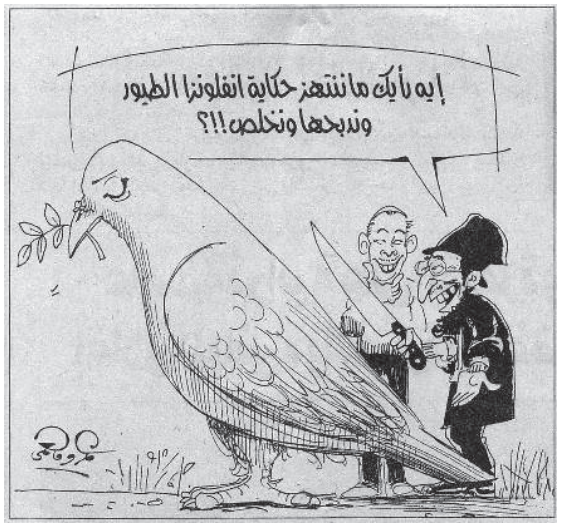

"Que penses-tu si nous profitions de I'histoire de la grippe aviaire, nous l'égorgeons et nous nous en débarrassons?" Le Juif, la colombe et le processus de paix Al-Akhbâr, 13 mars 2006

par la figure du juif religieux orthodoxe et de son compère, tous deux hilares devant leur prochain méfait. II s'agit ici de la réactualisation de l'image, traversant toute I'iconographie du complot américano-sioniste contre les pays arabes, du juif égorgeant la colombe.

\section{LE RÉSEAU SÉMANTIQUE DE LA GUERRE, DU KILLER VIRUS ET DU POULET TUEUR}

À en croire certains auteurs, I'humanité est entrée dans sa troisième transition épidémiologique marquée par l'avènement des maladies infectieuses émergentes et réémergentes (Barrett et al., 1998). Paradoxalement, cette dernière transition est initiée par un «contre-feu » de ce que la deuxième transition épidémiologique était supposée faire disparaître de l'horizon des sociétés occidentales : les maladies infectieuses ${ }^{13}$. Parallèlement, le « retour » des maladies infectieuses, symboliquement rapporté à la conjoncture du sida des années 1980, amènerait dans son sillage un retour marqué des métaphores de la guerre aux microbes. Mais, comparées aux guerres du passé, les guerres aux virus émergents seraient d'un autre type. Dépossédées par l'absence de vaccin contre le sida, la mutabilité des virus et la forte incertitude quant aux conditions même de leur émergence, les autorités sanitaires internationales et nationales auraient fait de la surveillance épidémiologique l'arme préventive de leur lutte contre ces « nouvelles » menaces sanitaires. Autrement dit, au réseau sémantique de la guerre d'éradication se serait substituée la catégorie du killer virus, traqué tel un criminel par des chasseurs de microbes organisés en réseau ${ }^{14}$.

II n'est peut-être pas aussi facile de lire les discours sur la santé publique suivant des paradigmes figés ${ }^{15}$. Et si la lutte contre les virus émergents mobilisait, aléatoirement ou de manière combinée, les ressources métaphoriques de la guerre, de la surveillance et de la police médicale?

13. En 1967, le "General Surgeon » aux États-Unis proclame la fin des maladies infectieuses. En 1970, après une campagne mondiale, I'OMS déclare l'éradication de la variole.

14. Pour se limiter à l'Égypte, nous renvoyons au récit d'un de ces chasseurs de virus, Snodgrass, 2003. 


\section{Vers une analyse de la production égyptienne de discours médiatiques sur les virus émergents}

L'analyse des idéologies postcoloniales de la santé fournie par l'historien Nicholas King insiste sur le jeu des similitudes et des différences entre ce qu'il nomme $I^{\prime}$ « emerging diseases worldview » et l'épidémiologie du " porteur sain » du xIx et début du xxe siècle (King, 2002 et King, 2004). L'une et l'autre partagent l'obsession des frontières et de leurs transgressions, I'identification de certaines nations ou certains groupes comme des réservoirs d'infection menaçants, et l'idéal de préservation des frontières territoriales par l'endiguement et la séparation. Mais, pour Nicholas King, les moyens de parvenir à la sécurité sont différents. L'épidémiologie du porteur sain, largement enrichie par le moment colonial, prescrivait certes la ségrégation, la quarantaine par l'instauration de cordons sanitaires. Dans un monde globalisé, l'idéologie postcoloniale des maladies émergentes trouve sa mise en pratique dans des réseaux déterritorialisés dont la fonction est d'assurer la surveillance globale et d'identifier les menaces émergentes ${ }^{16}$. Le cas de l'Égypte correspond assez bien à cette dernière configuration. Elle est un des lieux où la recherche en arbovirologie, grande pourvoyeuse de virus émergents, démarre après la Seconde Guerre mondiale sous l'impulsion de la Fondation Rockefeller, de l'université de Yale et de l'armée américaine ${ }^{17}$. Et les diagnostics virologiques d'H5N1 chez les oiseaux migrateurs et les humains y sont confirmés par la station de recherche de I'US Navy, appelée Namru-3, basée au Caire, après un premier diagnostic dans les laboratoires gouvernementaux de virologie.

Mais il n'est pas sûr que l'idéal de la surveillance se débarrasse aussi facilement que cela des pratiques de ségrégation territoriale, de quarantaine et de

15. Sur la difficulté de réduire les politiques de santé publique à des paradigmes en concurrence, Fintz, 2006. A fortiori la difficulté à opposer des paradigmes ou des modèles en santé publique vaut pour notre usage de la notion de police sanitaire que nous explorons plus loin. On se souvient, en effet, que la police médicale - ensemble de pratiques de surveillance, d'inspection et de collecte de données couplées à des interventions directes dans le domaine privé, familial et commercial - a été opposée au style de santé publique faisant davantage appel à l'éducation et à la sensibilisation. Les historiens opposaient le modèle britannique, respectueux de la liberté individuelle, au modèle continental européen, plus enclin à utiliser la force. Ils opposaient aussi le mercantilisme et le caméralisme, auxquels ils trouvaient une affinité élective avec la police médicale, à l'émergence du libéralisme et de la nouvelle santé publique. Sur ces débats historiographiques, Carroll, 2002.

16. Nous partageons moins la restriction de l'auteur qui décrit ces réseaux comme essentiellement informationnels.

17. Sur la naissance de ce réseau, Fintz, 2004-2005. On peut également noter la similitude de cette configuration avec la manière dont l'épizootie/épidémie de fièvre de la Vallée du Rift fut diagnostiquée et traitée à la fin des années 1970. 
cordons sanitaires. Et ce constat paraît peut-être d'autant plus fondé à mesure que I'on se situe au niveau des points de contact « hors d'Occident ». Sur ces sites, le virus qui est appréhendé sous le prisme d'une menace émergente pour les pays du Nord prend souvent les visages d'épidémies et d'épizooties meurtrières. Les mesures envisagées empruntent alors aux vieilles recettes du $\mathrm{XIX}^{\mathrm{e}}$ siècle $^{18}$. Le traitement médiatique de la grippe aviaire en Égypte a ainsi façonné une image de la guerre contre la grippe aviaire dans laquelle les autorités encerclent des foyers d'infection par des "cordons sécurisés », des porteurs sains sont détruits en masse quand il s'agit d'animaux, et des groupes et individus humains sont mis à l'index, en raison de leurs comportements, comme des vecteurs de l'infection.

On peut, sur un autre plan, remarquer une similarité entre l'interprétation écologique actuelle de l'émergence des virus et le tournant, opéré dans l'entredeux guerres, de certains épidémiologistes, bactériologistes et biologistes vers une interprétation multicausale des épidémies. Les deux interprétations font la part belle à une écologie de l'infection qui prend en compte à la fois les germes, I'hôte, le vecteur et l'environnement dans leurs interactions. Là où la bactériologie triomphante de la fin du $\mathrm{xIx}^{\mathrm{e}}$ siècle et les guerres $\mathrm{d}^{\prime}$ éradication du $\mathrm{xx}^{\mathrm{e}}$ siècle étaient obsédées par l'étude et la destruction d'un germe qui fournissait une cause spécifique et nécessaire à l'épidémie, l'écologie des virus émergents emprunte à l'interprétation des épidémies de l'entre-deux guerres, période caractérisée précisément par un pessimisme envers les stratégies d'éradication ${ }^{19}$. Au lieu d'envisager la relation d'un germe et d'un organisme sous les traits de l'invasion et de la guerre, le regard écologique de l'entre-deux guerres insiste plus sur I'avènement d'un équilibre entre l'hôte et le germe. L'épidémie n'est plus, sous ce regard écologique, que l' «épiphénomène » de la perturbation de l'équilibre par un ensemble de facteur soumis à un fort degré d'incertitude. Pour Andrew Mendelsohn cette redéfinition de l'épidémie s'est traduite par « the abandonment of the paradigm of pandemic cholera and plague, a whole imagination of epidemics as invasions of bacilli began to be given up » (Mendelsohn, 1998, p. 312). Qu'il s'agisse de la pandémie grippale de 1918, de la poliomyélite ou

18. Ce décalage entre «centres » et "périphéries », du point de vue d’une propension plus grande des administrations de la santé publique des régions périphériques à la gestion policière de l'épidémie, évoque ce qu'Anne Marie Moulin écrit à propos des débuts de la pasteurisation des sociétés coloniales : "Le véritable terrain d'application du programme pastorien d'immunisation n'a pas été l'hôpital Pasteur, ni même la métropole. Il s'est étendu d'emblée au-delà des frontières [...], dans l'espace ouvert aux «missionnaires» de l'Institut. Ceux-ci, pour la plupart des médecins militaires, se sont chargés du projet de vaccination et d'éradication des grandes endémies. Ils ont appliqué les règles bactériologiques d’une médecine de masse que leur idéologie libérale leur aurait interdit de pratique en métropole », Moulin, 1991.

19. Sur l'idée d'éradication, Moulin, 2004. 
des encéphalites, les sociétés européennes faisaient à présent l' « expérience des épidémies et pandémies comme survenant de l'intérieur »Ibid et non plus du lointain Extrême Orient. De ce point de vue, la comparaison de cette conjoncture avec celle de nos virus émergents contemporains présente des similitudes et des différences. La métaphore de l'équilibre a-t-elle vraiment rompu avec celle de l'invasion? Les métaphores de la guerre sont-elles vraiment absentes du réseau causal de la maladie évoluant vers la symbiose?

Seul I'examen de configurations socio-historiques caractérisées par des assemblages métaphoriques contextuels apparaît susceptible de fournir des clés de compréhension sur les points soulevés par ces questions. Prenons deux exemples. Dans son étude comparée du traitement médiatique de deux virus émergents, la fièvre aphteuse (2001) et le SRAS (2003) en Grande Bretagne, Brigitte Nerlich décrit deux types de récits différents. Alors que la lutte contre la fièvre aphteuse a été entreprise sous les auspices de la guerre, avec massacres d'animaux d'élevage, les métaphores de la guerre ont été quasi-absentes du cadrage médiatique de l'arrivée du SRAS. Le virus a plutôt été décrit à partir du registre de l'investigateur, du policier traquant le criminel et du chasseur pistant sa proie. Cette caractéristique fait dire à Brigitte Nerlich que : "Representing SARS as killer animal fitted with conceptions embedded in discourses of epidemiological investigation as hunting " (Wallis et Nerlich, 2005). Ce registre s'est doublé d'un registre de la lutte qui a emprunté aux métaphores du contrôle et du containment et non à celles de la guerre et de l'éradication. La fièvre aphteuse a, au contraire, ouvert une tout autre configuration métaphorique qui a emprunté au registre de la guerre lorsqu'il s'est agi de mobiliser l'opinion pour faire admettre l'abattage de masse d'animaux sains (Nerlich, 2004).

En Égypte, si les médias ont rapporté les processus épizootiques/épidémiques à la perturbation d'un équilibre social, la définition de l'épizootie comme invasion et, plus encore, le cadrage de la lutte comme une entreprise de guerre ont été une figure prééminente dans le discours médiatique. L'histoire du virus $\mathrm{H} 5 \mathrm{NI}$ ou, plutôt, du poulet tueur en Égypte nous permet d'identifier une configuration métaphorique hybride par rapport aux grands paradigmes de I'histoire de la santé publique. Le traitement médiatique de la crise de la grippe aviaire en Égypte a donné l'image d'un état entre guerre et paix. Cette " crise », médiatisée

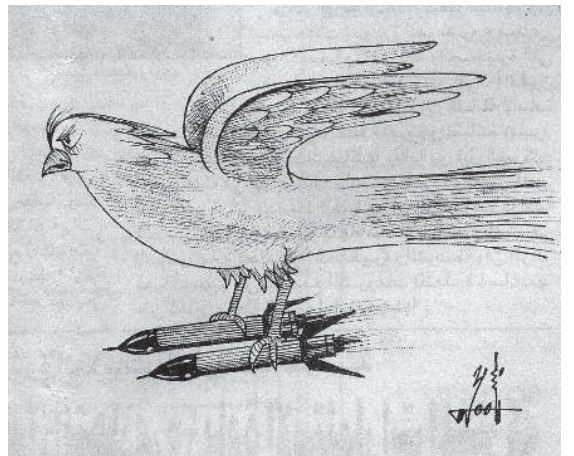

par la presse égyptienne, montre qu'il $\mathrm{n}^{\prime} \mathrm{y}$ a pas substitution de la surveillance épidémiologique à l'éradication des germes ni même au cordon sanitaire. Les procédés les plus modernes de surveillance épidémiologique existent au sein des laboratoires de virologie des ministères de la Santé et de l'Agriculture,

L'oiseau porteur de missiles

Al-Ahrâm, 24 février 2006 
du département de virologie de la station Namru-3, et du centre de référence OMS pour la grippe du Caire. Mais ce réseau coexiste avec une surveillance plus policière et la recherche des foyers d'infection, avec des descentes de police, des enquêtes, des opérations de mise en quarantaine, et avec l'abattage de masse entrepris sous le drapeau de la guerre aux poulets. De même, une épidémiologie médiatique de l'invasion (dessin ci-contre) coexiste avec une épidémiologie recherchant les causes à l'intérieur de la société égyptienne. Les explications de la genèse de l'épizootie ont ainsi oscillé entre la recherche d'un ennemi venant de l'extérieur et la stigmatisation d'ennemis intérieurs. La presse écrite égyptienne a encadré l'épizootie/épidémie en articulant les métaphores de la guerre et de I'investigation policière, non pas tant contre un virus que contre les oiseaux. Et, parmi eux, le poulet, plus que le virus, a figuré l'ennemi invisible.

Ce sont ces différents aspects que nous allons décrire dans la suite de cet article.

\section{Egypt under attack : le poulet tueur}

L'arrivée de la grippe aviaire en Égypte a montré que, sur le plan métaphorique, et du moins iconographique, les hommes peuvent se transformer en poulets. Il est significatif que le poulet, plus que le virus, ait été hissé sur les devants de la scène. Il était parfois question non du "virus tueur » (the killer virus), mais du "poulet tueur»(al-Dajâj al-Qâtil). Dans ses multiples occurrences dans les dessins de presse ou les gros titres, le poulet peut venir désigner des référents multiples, du simple citoyen au premier ministre, la victime comme I'agresseur, la proie comme le prédateur. Il faut donc être attentif aux différents registres créés par ces références multiples.

Ce zoomorphisme a sans doute été facilité par le caractère épizootique de I'infection, au moins jusqu'à ce que les premiers cas humains apparaissent dans la première quinzaine de mars 2006. Mais on ne peut négliger l'importance vitale de la volaille dans la vie quotidienne et I'alimentation des Égyptiens. Elevée de manière domestique, la volaille apporte souvent le seul revenu financier aux femmes qui l'élèvent, leur permettant ainsi de scolariser leurs enfants ou de garnir leur garde-robe. Lorsqu'elle est destinée à la seule consommation domestique, la volaille constitue aussi un apport assuré en protéines animales alors que les prix prohibitifs pratiqués sur la viande rouge en rendent I'accès difficile. Dans ce contexte, I'annonce de I'arrivée de la grippe aviaire en Égypte marque une inversion de la relation entre humains et oiseaux. La réciprocité de la relation s'efface alors au profit d'une relation évoluant vers le parasitisme destructeur et la prédation au sein de laquelle le poulet est devenu une menace pour la vie de celui qui l'héberge et l'élève.

On ne saurait pourtant réduire l'importance de la figure du poulet à sa seule valeur nutritive ou à l'histoire quasi-naturelle de la coévolution des Égyptiens et de leurs volailles. En effet, la figuration de l'épizootie par le poulet et les 
oiseaux dans l'iconographie médiatique est aussi le produit de la politique d'abattage des volailles endossée par le gouvernement égyptien et par laquelle lutter contre le virus H5N1 est revenu à égorger les porteurs du virus avérés et potentiels : les oiseaux. Le poulet et, plus largement, les oiseaux ont pu ainsi figurer l'ennemi à abattre. La création de la figure du poulet épidémique ou du poulet tueur, induite à la fois par la politique d'abattage de masse, le traitement médiatique de la grippe aviaire et le comportement des consommateurs réticents à acheter de la viande blanche en dépit des conseils des politiques (réticence induite par la culture du mensonge maniée par les gouvernements successifs), n'a pas été sans entraîner des conséquences économiques brutales que les producteurs de volaille ont naturellement été les premiers à dénoncer.

Du point de vue économique, le secteur avicole connaît une croissance exponentielle depuis le milieu des années 1980. Ahmad al-Khayât, directeur manager de Cairo Poultry Company (sharikat al-qâhira li-intâj al-dawâjin), un des leaders du secteur, revenait dans Al-Fajr sur le développement de celui-ci, qu'il fait remonter aux années 1960 : 68000 élevages, une production annuelle de 750 millions de volailles estimée à 17 milliards de LE, un million de main d'œuvre directe et autant de main d'œuvre indirecte, I'autosuffisance acquise en 2002, date à laquelle ont commencé des exportations vers 12 pays arabes, qui atteindraient 24 \% de la production en 2004. Tout en minimisant l'impact de la grippe aviaire sur la santé humaine par rapport au demi million de décès imputable à la grippe humaine chaque année, il reprochait à l'État et aux médias d'avoir effrayé le peuple égyptien en produisant « une image du poulet comme s'il était l'épidémie » et d'avoir ainsi précipité la perte du secteur ${ }^{20}$.

"La grippe conquiert l'Égypte ${ }^{21}$ (al-anfilwanzâ taghzû misr) lance Al'Arabî. L'arrivée de la grippe aviaire en Égypte a pu être lue comme une invasion, comme dans ce dessin d'Al-Wafd figurant un escadron d'oiseaux larguant leurs bombes virales au-dessus de la ville du Caire.

Il n'en demeure pas moins qu'un fort degré d'incertitude planait sur les véritables envahisseurs : s'agissait-il des oiseaux migrateurs, chez qui les prélèvements n'avaient pu jusque là déceler aucun cas positif ? Ou bien fallait-il chercher la source du côté d'un ennemi intérieur? Ce qui est sûr est que cette invasion incertaine a provoqué la peur : " la grippe tueuse » (al-anfilwanzâ alqâtila $)^{22}$ ou encore «le virus mortel » (al-fayrûs al-qâtil) ${ }^{23}$ ont incité à « la peur

20. Al-Fajr, "Le gouvernement a amené le démon de la grippe aviaire, à lui de le chasser », 27 février 2006.

21. «La grippe aviaire conquiert l'Égypte... et la fièvre aphteuse en prend le chemin », Al-'Arabî, 2 avril 2006.

22. "La grippe tueuse tape à la porte de l'Égypte », Al-Usbû', 20 février 2006, en référence aux « 40 millions » de morts de la grippe espagnole en 1918.

23. «Les commerçants : Nous avons fermé nos boutiques, le virus tueur a envahi nos maisons ", Nahdat Misr, 22 février 2006. 


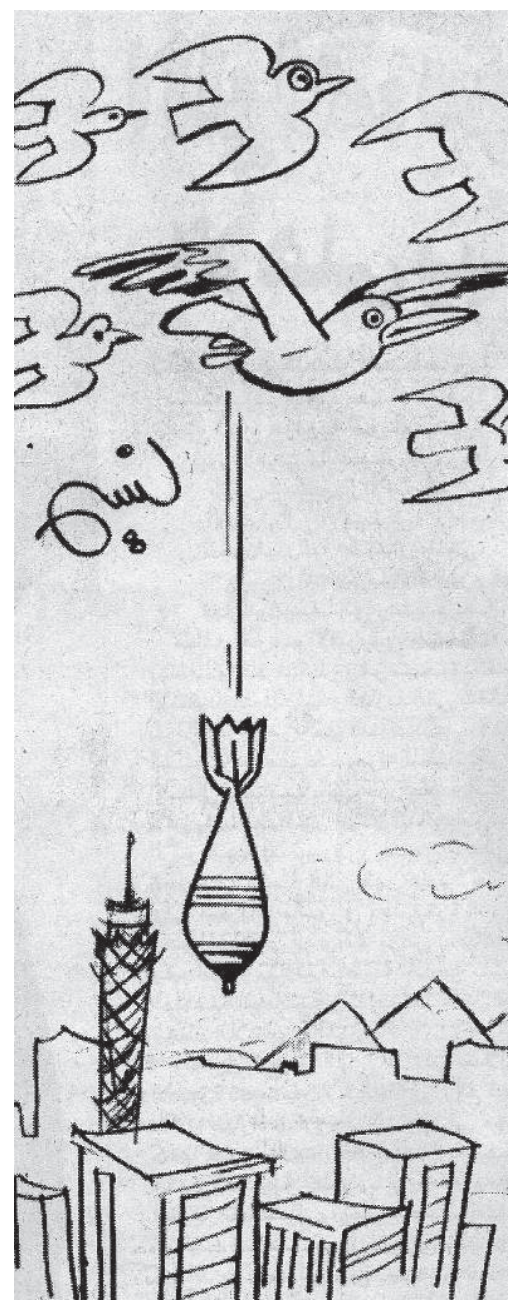

Le virus est une bombe

Al-Wafd, 24 février 2006

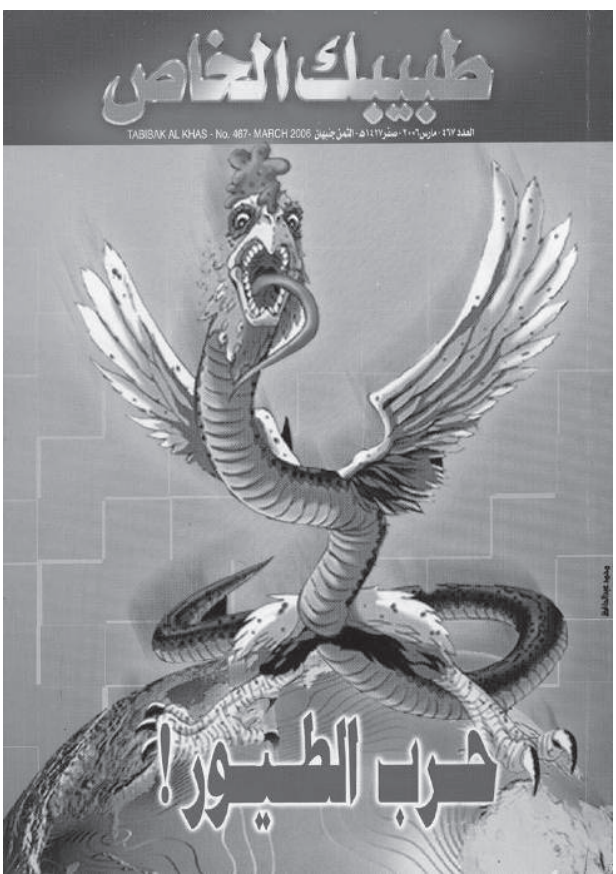

"Guerre aux oiseaux "

Image de la peur dans la presse spécialisée

Tabîbak al-Khâs, 467, mars 2006

du poulet » (ru'b al-firâkh $)^{24}$, à «la peur tueuse »(al-ru'b al-qâtil) ${ }^{25}$, à « la folie de la grippe aviaire » (al-hawas anfilwanzâ altuyûr $)^{26}$, à " l'effroi » $\left(a l-z u^{\prime} r\right)$, ou encore au sentiment de « danger»(al-khatar) et de « choc» (al-sadma).

La mobilisation de la peur n'est pas restée cantonnée à la presse générale égyptienne, mais a bien été partagée par l'ensemble des journaux. La presse médicale spécialisée n'a pas été en reste, comme en témoigne cette couverture du mensuel Tabîbak al-Khâs montrant un monstre hybride à tête de poulet montée sur un corps de serpent dominant le monde. Cette présence extraordinaire de la grippe aviaire dans un journal de vulgarisation professionnelle n'en

24. Al-Usbû', 20 février 2006. Ou "peur des oiseaux » (ru'b al-tuyûr) à la Une de Al-'Arabî, 19 février 2006.

25. Al-'Arabî, 19 février 2006.

26. Éditorial Al-Usbû', 20 février 2006 ; Une de Al-Missâ'î, 21 février 2006. 
indique pas moins l'idée d'une présence, impossible à localiser et à prévoir, de la grippe aviaire. L'infection est en fait latente, à la fois hors des frontières et à I'intérieur. Cette couverture offre ainsi un bel exemple de la manière dont le virus $\mathrm{H} 5 \mathrm{NI}$ et les oiseaux en sont venus à figurer une catastrophe émergente.

La figure du serpent associée à celle du poulet n'est pas sans évoquer aussi l'idée du poulet venimeux ou empoisonné, rejoignant ainsi la question de la pollution alimentaire, thématique médiatique hors du cadre de cet article.

$L^{\prime}$ « attaque » de grippe aviaire est parfois représentée comme semblable à une attaque terroriste dans laquelle le virus est la bombe et le poulet le kamikaze. C'est bien la guerre au terrorisme qui est exprimée par certaines métaphores picturales et verbales de la grippe aviaire.

"Les dix commandements pour lutter contre le «terrorisme» de la grippe aviaire»

Le poulet kamikaze et le " terrorisme » de la grippe aviaire Uktûbar, 26 février 2006

L'image du poulet kamikaze, en couverture de l'hebdomadaire Uktûbar, rend bien compte de l'association forte entre maladies infectieuses émergentes et terrorisme, telle qu'elle commence à prévaloir tant dans le domaine de la santé publique internationale que dans celui de la sécurité (Cooper, 2006). Contrairement à des dessins présentés plus haut, il ne s'agit pas cette fois d'un oiseau migrateur ou, tout au moins, doté d'une grande capacité de vol lui

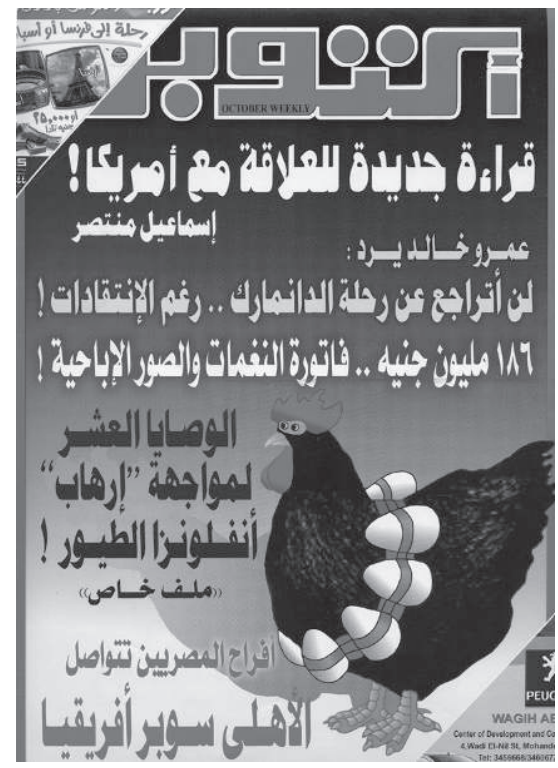
permettant de franchir les frontières. Il s'agit d'un oiseau domestique, le poulet, inscrit dans les cultures populaires égyptiennes depuis des générations. La menace virale n'est pas ici extérieure aux frontières territoriales égyptiennes, elle est au contraire interne à la société. La menace virale, comme la menace terroriste, peut aussi être endogène à la société égyptienne.

Une anecdote tiré de $A /$-Ghad rend compte comment, dans le quartier de Manyal au Caire, les habitants ont été alarmés par la vision de deux canards déambulant dans les rues. Certains d'entre eux ont appelé la sécurité centrale (al-amn al-markazî) qui est venue établir un cordon sanitaire dans le quartier et aurait distribué des "gaz lacrymogènes ». Interloqué et quelque peu moqueur, le journaliste écrit : "Voir un oiseau revient à voir un terroriste qui porte des armes de destruction massive. Les habitants ont été pris de panique devant deux canards et ont appelé le ministère de I'Intérieur » (Al-Ghad, 29 mars 2006). 
Et, lorsque fin avril, une série d'attentats frappe la ville de Dahâb et le nord Sinaï, le journal Al-Akhbâr intitule un article sur les condamnations unanimes des attentats par les partis politiques : "Les oiseaux des ténèbres [tuyûr alzalâm]... ne peuvent porter atteinte à l'Égypte » (Al-Akhbâr, 27 avril 2006).

La double face de la sécurité sanitaire égyptienne: I'armée et la police

Si l'imagerie de la grippe aviaire a pu figurer des situations de guerre, telles que la " guerre de civilisation » des caricatures, la guerre en Irak ou I'occupation de la Palestine, c'est plus encore le traitement médiatique de la lutte (al-muwâjiha) gouvernementale contre l'épizootie qui a contribué à produire I'image d'une guerre contre la grippe aviaire. L'autonomie médiatique par rapport à l'action gouvernementale est bien relative dans ce cas de crise sanitaire. Le développement de métaphores militaires et policières correspond, en effet, à la division du travail de la lutte. Armée et forces de sécurité y ont pris la place la plus importante, les équipes des ministères de la Santé ou de l'Agriculture apparaissant au second plan.

Avant même la reconnaissance officielle de la présence du virus H5N1 à la mi-février 2006 par le ministre de la Santé, son prédécesseur, 'Awâd Tâg al-Dîn, sous le haut patronage du président Moubarak, a mis en place un Comité suprême de lutte contre la grippe aviaire (al-lajnat al-'uliya li-mukâfahât anfilwanzâ al-tuyûr) alors que la menace virale se rapproche des frontières égyptiennes et est identifiée en Turquie orientale à la fin de l'année 2005. Ce Comité, à vocation interministérielle, regroupe les ministères de la Santé (le ministre de la Santé présidant le comité), de l'Agriculture, de l'Environnement, de la Défense, de l'Intérieur, des Affaires étrangères, des Transports, de l'Aviation et de I'Information. Y participent également un représentant du bureau régional de I'OMS pour le Moyen Orient et un autre de la station de recherche de I'US Navy, Namru-3, basée au Caire depuis 1947. Les premières mesures prises par ce comité ressortissent du domaine de la prévention comme l'interdiction de l'importation de volaille en provenance de Turquie et de Grèce, la réactivation des observatoires des oiseaux migrateurs dans les IBA (Important Birds Areas) ou encore l'interdiction de la chasse à ces mêmes oiseaux. D'octobre 2005 à février 2006, les représentants de ce comité ne se lasseront pas de répéter qu'ils ont sous la main un plan d'action en cas d'arrivée du virus.

Le Comité Suprême s'est réuni avec une fréquence hebdomadaire jusqu'au remaniement ministériel de la fin décembre 2005, qui a vu l'éviction du ministre de la Santé Tâg al-Dîn ${ }^{27}$. Son successeur, Hâtim al-Gabalî, a reconnu plus tard que la fréquence des réunions s'est ralentie au cours du mois de janvier

27. Sur la « crise » du ministère de la Santé en 2005, Fintz, 2006 b. 
lors de sa prise de fonction. II semble également que la participation n'ait pas atteint le même degré d'assiduité pour tous les acteurs du Comité (Rûz al-Yûsif, 3 mars 2006) ${ }^{28}$. De son côté, le ministre de l'Agriculture revient en avril sur la période de transition gouvernementale de janvier et concède que la grippe aviaire ne faisait pas alors partie des priorités, son ministère étant mobilisé par les questions de l'eau et de la terre. Il concède aussi avoir manqué d'informations sur l'infection en raison du renouvellement de son ministère lié à son arrivée (Al-Jumuhûriyya, 13 avril 2006).

La donne change au mois de février 2006 quand la " guerre » à la grippe aviaire est déclarée après que I' « invasion » virale a été reconnue. La panoplie des mesures s'alourdit de mesures préventives plus radicales, comme la fermeture des boutiques de volaille, la destruction des poulaillers et des nids, l'abattage des élevages suspects ou infectés, le dédommagement des propriétaires des élevages détruits, I'interdiction de transport des volailles entre les gouvernorats et la pulvérisation de produits désinfectants sur les lieux touchés et sur les pneus des véhicules franchissant les frontières des gouvernorats $^{29}$.

«Caricature de lecteur: - C'est... le ministre de la Santé...

il a déclaré la guerre à la grippe aviaire » Mythologie de la guerre ou donquichottisme ? Al-Akhbâr, 13 mars 2006

Le dessin ci-contre illustre bien ce départ en guerre du ministère de la Santé ; il en montre également les limites. Armé de son sabre et de son bouclier, image mythique du conquérant arabe, le ministre est en même temps démuni face aux pigeonniers autour desquels s'ébat un essaim d'oiseaux. En fait,

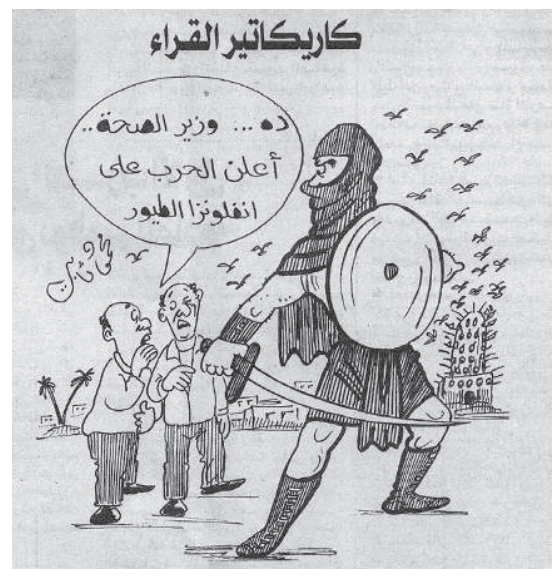
comme nous le verrons plus bas, le ministère de la Santé aura besoin de l'armée et de la police pour revêtir les habits de guerrier sans lesquels sa campagne contre la grippe aviaire apparaîtrait comme du donquichottisme.

La politique d'abattage va devenir la voie privilégiée par le gouvernement - au grand désespoir de l'Union des producteurs de volaille (itihâd muntijî al-dawâjin) et des firâkhiyin, boutiquiers spécialisés dans la vente de volaille vivante. Des manifestations devant le Parlement ou devant le Conseil des gouverneurs émailleront la discussion de ces mesures : de mi-février à mi-mars,

28. Par ailleurs, les ministres chargés de l'économie rejoignent le Comité après I'annonce officielle, toujours d'après ce journal.

29. Par exemple à l'entrée du Fayoum, région réputée pour son canard. 
le chiffre avancé par le ministère et des organes de presse de toute tendance politique atteint 15 millions d'oiseaux abattus ${ }^{30}$.

La politique d'abattage est supposée suivre deux voies. Les oiseaux qui sont identifiés comme infectés sont brûlés et inhumés. Les oiseaux sains sont de leur côté égorgés par le réseau des abattoirs. En ville, tous les élevages situés à moins de $0.5 \mathrm{~km}$ sont censés être abattus, la distance pouvant aller dans certaines circonstances jusqu'à 3 km. Les deux modalités de la politique d'abattage répondent aussi à un critère d'indemnisation mis en place par le gouvernement. Les propriétaires d'élevage ne sont en effet dédommagés que pour les oiseaux sains. Le gouvernement a d'abord annoncé qu'il rachèterait la production des oiseaux sains au prix du marché, puis il a fixé la somme de $5 \mathrm{LE}^{31}$ par poulet sain et, au mois d'avril, de nombreux journaux rapportaient des plaintes d'éleveurs affirmant qu'ils n'avaient été indemnisés, s'ils l'avaient jamais été, qu'à hauteur de 1 LE par poulet ${ }^{32}$.
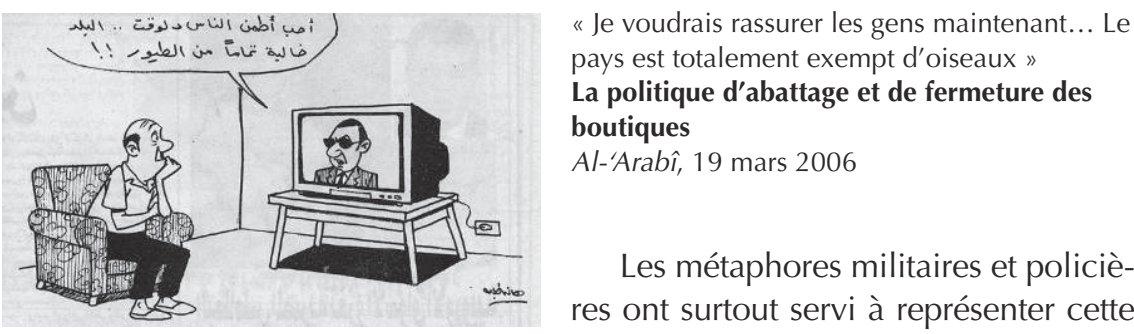

« Je voudrais rassurer les gens maintenant... Le pays est totalement exempt d'oiseaux »

La politique d'abattage et de fermeture des boutiques

Al-'Arabî, 19 mars 2006

Les métaphores militaires et policières ont surtout servi à représenter cette politique d'abattage, de destruction des élevages et de surveillance des élevages récalcitrants en milieu urbain. Elles ont symbolisé la manière dont l'action contre le porteur de virus, le poulet, est venue supplanter tout autre type d'actions dans l'imaginaire médiatique durant le premier mois de l'épizootie. Le moyen, comme le suggère ce dessin, est devenu la fin. Mais, par la présence de la télévision et du locuteur aux lunettes noires, le caricaturiste insiste également sur l'importance des médias dans la crise de la grippe aviaire. L'affirmation selon laquelle le pays serait exempt d'oiseaux, une fois insérée dans le contexte choisi par le caricaturiste, reste ainsi soumise à l'épreuve de réalité que les journaux égyptiens ne se sont pas privés de fabriquer pour relever le caractère parfois hypothétique de la politique d'abattage.

Nous ne discuterons pas ici la deuxième mesure préventive d'ampleur prise par le Comité suprême lorsqu'il a décidé d’utiliser la vaccination des

30. Chiffre avancé dans Al-Usbû', 13 mars 2006 et dans Al-Musawwar, 31 mars 2006. Selon ce dernier " l'équivalent de ce qui a été abattu en Europe et en Asie du Sud-est serait de 2003 à $2006 »$.

31. «Le gouvernement a décidé 5 LE pour un poulet... La devinette des dédommagements ", Al-Wafd, $1^{\text {er }}$ avril 2006.

32. Les deux voies de la procédure d'abattage et le procédé de dédommagement sont exposées par Amîn Abâza dans Al-Misrî al-Yawm, 20 février 2006. 
volailles à grande échelle. Cette mesure a été plus tardive (elle débute officiellement le 20 mars 2006) et plus controversée parmi les membres du Comité Suprême, et entre le Comité et les éleveurs. Les métaphores de la vaccination ont surtout fait appel aux images de la corruption et ont fait moins de place aux métaphores guerrières et/ou policières.

\section{Métaphores militaires}

Dans le discours public tenu sur l'action du gouvernement, celui-ci « assiège » (hisâr) les «foyers » (al-ba'ar) de l'infection, il " combat» (kâfaha) l'épidémie en se préparant (al-isti'dâdât) telle une armée, ou encore il met en place des dispositifs de "surveillance » (al-istitlâ) de la progression épidémique et de "prévention» (al-Wiqâya) énumérés ci-dessus. Chaque ministère annonce la création d'unités spéciales : des " unités environnementales » (al-wahadât al-bî́'iyya) pour le ministère de l'Environnement ou encore des «brigades» (al-firâq) pour les ministères de la Santé et de l'Agriculture.

Mais ce sont les forces armées et policières qui ont pris en charge le "nettoyage» (au sens militaire du mot, al-tathîr) des nids (al-'ichach) et pigeonniers (abrâj al-hamâma) et leur " anéantissement » (al-qadâ') ainsi que I'incinération des cadavres d'oiseaux et leur ensevelissement dans des " caveaux sanitaires» (al-madâfin al-sihiyya). Le 22 février, le Conseil des ministres décide de faire appel aux forces armées pour se débarrasser des oiseaux morts ${ }^{33}$. Et le ministre de la Santé rendra hommage, dans un entretien donné en avril à $A l$-Ahrâm, à la participation des forces armées dans l'enlèvement des carcasses de poulets ${ }^{34}$.

«Le gouvernement a résolu le problème, il a pris les oiseaux et nous a laissé la grippe»

Dénonciation du pillage opéré par les forces armées Al-Dustûr, 29 mars 2006

Malgré un consensus autour de l'action de l'armée, son intervention a pu être dépeinte sous la figure de l'État pillant les ressources animales du pays.

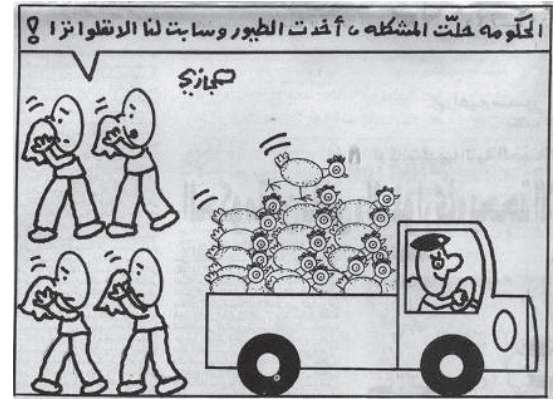
Le jeu permis autour de l'inhumation des poulets décédés ou infectés et de

33. "Les forces armées fournissent de grands véhicules pour transporter les volailles dans les abattoirs et les congeler gratuitement », Al-Ahrâm, 22 février 2006 et AlMisrî al-Yawm, 23 février 2006.

34. Al-Ahrâm, 9 avril 2006. Mais les hommages sont aussi plus précoces : «Poursuite des efforts pour encercler la grippe aviaire - Recul des notifications sur les oiseaux morts dans les gouvernorats et éloge des efforts des forces armées pour y faire face ", Al-Ahrâm, 2 mars 2006. 
l'égorgement des poulets sains destinés ensuite à la consommation pouvait en effet laisser imaginer que certaines marges de tolérance étaient mises à profit pour détourner la viande afin d'alimenter les milliers de soldats égyptiens soumis à la diète ou de la commercialiser dans les réseaux de l'armée.

Les aspersions de produits désinfectants sont une des mesures les plus spectaculaires de l'action gouvernementale. Les photos d'équipes de pulvérisation ne seront cependant disponibles dans la presse qu'à partir du premier décès humain, lorsque les journaux dépêcheront sur place des journalistes pour rendre compte de la situation dans son village, Nawâ, situé à une trentaine de kilomètres au nord du Caire. C'est principalement le journal Rûz al-Yûsif qui publiera les photos de sprayers en action devant l'appareil photo.

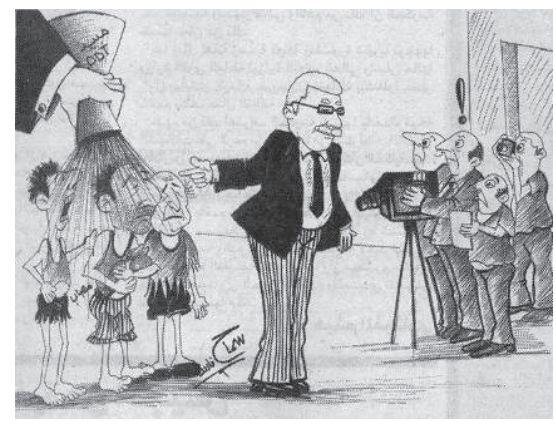

«Insecticide DDT»

Nazîf dépouille les pauvres devant la presse internationale

Al-Ghad, $1^{\text {er }}$ mars 2006

L'impact médiatique des pulvérisations d'insecticide est aussi bien dépeint par cette caricature d'Al-Ghad dans laquelle le premier ministre présente fièrement à des journalistes quelque peu interloqués la manière dont il se débarrasse de la grippe aviaire. Dans le dessin, ce n'est cependant pas un produit chloré qui est pulvérisé sur les Égyptiens (comme ce qui est effectivement pratiqué), mais du DDT, insecticide hautement symbolique des politiques sanitaires et agricoles menées en Égypte depuis le milieu de la Seconde Guerre mondiale ${ }^{35}$. En santé publique, la lutte contre le typhus puis contre le paludisme pendant cette guerre a représenté un enjeu majeur pour les autorités sanitaires alliées et le gouvernement égyptien, réformant ainsi la culture matérielle de l'épouillage ${ }^{36}$. On est fortement tenté de lire cette caricature à deux niveaux. Elle peut se lire au sens littéral, en référence à l'activité d'épouillage proprement dite. Mais elle peut aussi être vue comme l'action de rendre pauvre, de dépouiller, et elle exprimerait la "destruction » et la mise au chômage des travailleurs du secteur agricole induite par les décrets gouvernementaux.

35. Sur la naissance du complexe agriculture - industries de pesticides - santé publique en Égypte, Mitchell, 2002. Avec l'Algérie, le Mexique et I'Italie, l'Égypte fut en effet un site important sur lequel la théorie de l'éradication des maladies vectorielles par le DDT fut testée pendant la Seconde Guerre mondiale. Voir sur cette histoire, Stapleton, 2000 et Weindling, 2000.

36. Avec la substitution de pratiques mobiles d'aspersions d'insecticide au réseau fixe et rigide des stations d'épouillage. 
Opération de santé publique, l'intervention des forces armées dans la crise est aussi une opération de communication. Elles apparaissent, dans la presse gouvernementale, comme les garantes de la richesse avicole du pays en ayant ouvert leurs abattoirs et congélateurs ou en ayant racheté la production aux éleveurs sinistrés ${ }^{37}$.

\section{Métaphores policières : encerclement/siège (Hasr, Hisâr) et police sanitaire}

Le ton semblait donné. En janvier 2006, alors que l'inquiétude grandit dans la presse sur l'invasion prochaine du pays par la grippe aviaire, le journal Sût al-Umma fait part à ses lecteurs de l'aventure d'un éleveur du gouvernorat de Sharqiyya qui a perdu 1000 de ses poulets. Pour le journal, cet holocauste est le signe que la grippe aviaire est apparue en Égypte ${ }^{38}$. Audelà de la mise en évidence de jeux d'annonces, des logiques du scoop et de la promotion apologétique du président Moubarak, le récit est important dans la mesure où il décrit l'action gouvernementale sur le registre d'une opération de police.

Malgré des fax, restés sans réponse, envoyés aux services vétérinaires, à la représentation locale du ministère de la Santé, à la justice et au parquet de Zagazig, le propriétaire, inquiet de la mort subite de ses poulets, se décide à demander de l'aide auprès de la présidence de la République. Comme par magie, des représentants de la police sont dépêchés sur place et un comité local est formé qui déclare aussitôt l'état d'urgence. "L'élevage a été conservé, écrit le journal, mais mis sous surveillance renforcée de la part des forces de sécurité [quwât al-amn] » qui assiègent la propriété. Les gouvernorats limitrophes ferment leurs frontières et y placent des " guets » (kamîn), les gouverneurs « donnent leurs instructions aux directions de la sécurité (mudîriyyât al-amn) » ou encore déclarent eux aussi l'état d'urgence. La question de la grippe aviaire, telle qu'elle s'ébauche à ce moment-là, est donc surtout une question de police sanitaire résolue par les forces de sécurité, et non par les services sanitaires ou vétérinaires. Lutter contre la grippe aviaire revient, dans ce contexte, à faire advenir le règne de la sécurité dans le pays.

La métaphore policière de I' " encerclement » ou du "cordon de sécurité » est ici particulièrement riche. Son usage permet en fait de cadrer un style de gouvernement en soulignant le passage des pratiques de lutte contre

37. "Nos forces armées participent à la lutte contre la grippe aviaire », Al-Akhbâr, 22 avril 2006. Les forces armées égyptiennes sont en même temps un des plus gros éleveurs de volaille dans le pays, produisant 108 millions d'œufs par an ainsi que 400 tonnes de viandes blanches distribuées dans 120 lieux de vente, selon le général médecin vétérinaire des forces armées interrogé par le journal.

38. "L'apparition de la grippe aviaire à Sharqiya dévoile la fausseté des déclarations du ministre de la Santé et provoque la panique [Zu'r] dans tous les gouvernorats de la République », Sût al-Umma, 23 janvier 2006. 
la grippe aviaire aux pratiques policières face aux manifestations de rue, de la biosécurité à la sécurité tout court. Ce sont en effet ces deux termes qui sont utilisés par les policiers ou les manifestants pour rendre compte de la pratique policière consistant à fermer tout un quartier suite à un préavis de manifestation afin d'empêcher les manifestants potentiels de s'y rendre ou encore à cerner un groupe de manifestants par les forces de police, étape préalable à leur tabassage en règle une fois pris au piège.

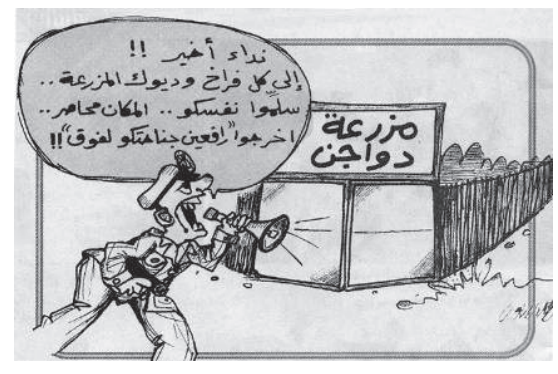

«Le policier : Dernière sommation ! À tous les poulets et coqs de l'élevage... Rendez vous... Le lieu est encerclé... Sortez les ailes en I'air !!"

Assaut d'un élevage de poulets

Sabâh al-Khayr, 28 février 2006

Pour encercler les foyers de l'infection et empêcher sa propagation, la presse rend également compte d'initiatives gouvernementales telles que des "descentes de police » (mudâhamât), des " campagnes de perquisition » (hamalât al-taftîch) afin de traquer les propriétaires de volaille. La procédure à suivre dans le diagnostic et l'encerclement de la maladie consiste d'ailleurs à confier à la police, voire à la justice, la destruction des élevages infectés. Ainsi, une fois que les prélèvements effectués dans les élevages suspects ont été testés positifs, le laboratoire central du ministère de l'Agriculture doit en principe prévenir les autorités de police pour qu'elles se rendent sur les lieux infectés, les isolent et entreprennent la destruction des poulets sous peine d'amende.

L'interdiction de transport de volailles vivantes entre les gouvernorats est également une mesure pour laquelle les métaphores policières sont utilisées dans la mesure où elle concerne la surveillance de frontières intérieures, dont la violation constitue un acte de contrebande (al-tahrîb). Et, pour rendre compte de cette action de surveillance, c'est le ministère de l'Intérieur qui est I'acteur le plus pertinent ${ }^{39}$.

Bien sûr, comme de nombreux articles le mentionnent, l'effectivité du contrôle policier a bien souvent varié selon les situations, de la même façon qu'ont varié les modalités d'application du décret d'interdiction de transport de volailles entre les gouvernorats. La presse accusera le gouvernement de

39. Par exemple, "Saisie de 45000 oiseaux vivants avant leur contrebande entre gouvernorats " par la Section de la sécurité économique du ministère de l'Intérieur, Al-Wafd, 26 mars 2006. Le vice-ministre de I'Intérieur annonce la « Saisie (dabt) de 1400 poulets morts de la grippe aviaire à côté d'un abattoir », Al-Jumuhûriyya, 10 avril 2006 ; "Contrebande (tahrîb) de poulets infectés dans des véhicules de mobilier», Al-Wafd, 18 avril 2004. 
"Campagnes d'élimination des nids à cause de la grippe aviaire Le policier : - Parfait chef, cette cabane n'a pas d'oiseaux. Seul un humain y habite avec sa famille »

L'oiseau sur le toit : État fort/État faible Al-Naba', 5 mars 2006

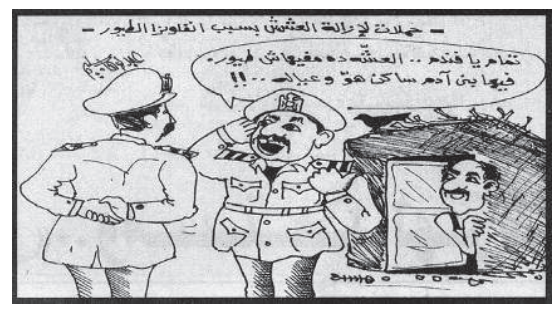

« négligence » $\left(a l-i h m a ̂ a^{40}\right)$ dans la saisie des véhicules transportant des oiseaux morts (Al-Misrî al-Yawm, 12 mars 2006). Ce décalage entre une rhétorique militaire et policière donnant l'image d'un État fort et le caractère " désordonné » de la politique d'abattage est bien illustré dans le dessin ci-dessus où l'on voit l'officier de police affirmer avec certitude à son supérieur que la fouille de la cabane s'est révélée négative, alors même que le lecteur distingue un oiseau perché sur le toit.

La police sanitaire n'est pas cantonnée à la recherche des foyers d'animaux infectés, elle est également utilisée pour entourer le malade et l'infecté d'un halo protecteur et préventif. Une anecdote rapportée par deux quotidiens en témoigne. Elle concerne la fuite d'une patiente qui avait été référée à l'hôpital de Qasr al-'Aiynî au Caire. "La police poursuit une dame suspectée d'être infectée par la grippe aviaire - Fawziya s'est enfuie de Qasr al-'aynî avant les résultats de son examen... et le parquet enquête avec les médecins » (Al-Misrî al-Yawm, 22 mars 2006) ${ }^{41}$.

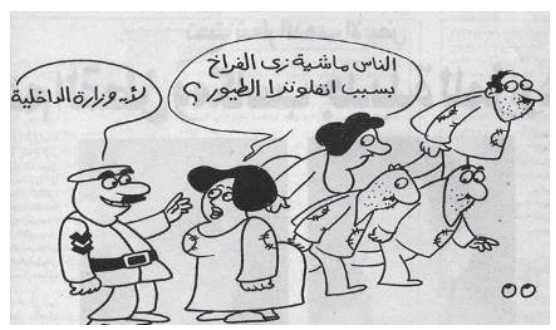

«- La Dame : Les gens marchent comme des poulets à cause de la grippe aviaire?

- Le policier : Non, [à cause] du ministère de

I'Intérieur»

L'Égypte assommée ?

Al-'Arabî, 19 mars 2006

L'impact de la politique d'abattage ne s'est bien entendu pas seulement fait sentir sur les oiseaux, leurs propriétaires en ont également fait les frais - ce qui a pu faire dire à certains titres de presse que les Égyptiens étaient « égorgés " par les décrets gouvernementaux au même titre que leurs animaux l'étaient par le couteau. À l'arbitraire des pratiques d'abattage répondait l'arbitraire des dédommagements promis aux sinistrés par le gouvernement. Et dans la mesure où la gestion de la crise fut confiée aux forces de sécurité, il n'en fallait pas moins pour montrer une nouvelle fois l'arbitraire de principe

40. Ce mot pouvant signifier tout autant le comportement irrégulier d'éleveurs ou de commerçants que le comportement crapuleux des forces de sécurité elles-mêmes.

41. L'histoire est également rapportée par al-Ahrâr du même jour. 
de l'administration de l'État policier égyptien. En suggérant un glissement entre la manière dont le gouvernement égyptien agit envers les poulets et celle dont les forces de sécurité se comportent avec les citoyens, ces deux dessins suggèrent que le gouvernement égyptien traite ses citoyens comme des animaux.

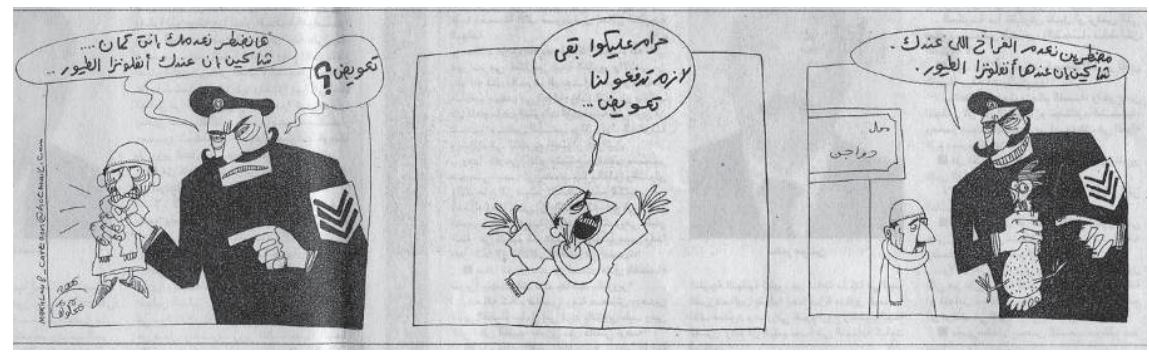

" - Le policier : On est obligé d'abattre les poulets qui sont chez toi. On craint qu'ils n'aient la grippe aviaire.

- Le vendeur de poulet : Honnis soyez-vous ! Il vous reste à nous donner des dédommagements... - Le policier : Des dédommagements ? On va être obligé de t'abattre toi aussi... On craint que tu n'aies la grippe aviaire »

Al-Dustûr, 8 mars 2006

\section{UNE « GUERRE AUX PAUVRES »? STRATÉGIES GOUVERNEMENTALES D'IMPUTATION}

Après un bref moment d'euphorie ironique laissant à penser qu'avec l'effondrement du prix de la viande de poulet, même les pauvres pourraient se procurer la précieuse denrée, il est devenu de plus en plus évident, du côté de certains segments de la presse partisane et indépendante, que l'épizootie avait fourni au gouvernement l'occasion de lancer une " guerre aux pauvres ». Pour le nassérien Al-'Arabî, "le régime Moubarak répète l'automne de Sadate ${ }^{42}$. Les jeux médiatiques d'imputation des responsabilités dans la propagation de l'épizootie laissent transparaître la tendance des représentants de l'État à mettre en cause la culture populaire égyptienne, accusée de produire les conditions propices aux épizooties ${ }^{43}$. La stigmatisation des femmes constitue, ensuite, un second répertoire gouvernemental d'imputation : il leur est reproché de contourner les décrets d'abattage des élevages infectés, voire de leur contrevenir délibérément. En filigrane, sous la grippe aviaire couve une " guerre sociale » opposant les élites au peuple qu'elles prétendent certes représenter mais pour lequel elles ont du mal à cacher leur mépris.

42. En référence à la révolte du pain en 1977, Al-'Arabî, 30 avril 2006.

43. Entretien de Hâtim al-Gabalî dans Al-Ahrâm, 9 avril 2006. 


\section{Le peuple et ses poulets}

Au ministère de l'Agriculture, il apparaît clairement que les difficultés à maîtriser la grippe aviaire s'expliquent par la forte proportion de l'élevage domestique (tarbiyyat al-dawâjin fî-l-manâzil). " L'Égypte est un cas spécial [hâla khâsa] ", affirmait le ministre de l'Agriculture dans un entretien à Al-Misrî al-Yawm ${ }^{44}$. Et cette particularité est avant tout celle des citoyens égyptiens s'adonnant à cette " fâcheuse habitude » (al-âda al-sayi'a) de l'élevage domestique, de la vente de poulets vivants et de l'égorgement en public. Et le projet gouvernemental de favoriser l'importation de poulets congelés montre qu'il est disposé à mettre fin à ce mode de production.

Dans un entretien accordé à Al-Jumuhûriyya le 13 avril 2006, le ministre de I'Agriculture reconnaît que sur les 45 à 50000 élevages que compte l'Égypte, seuls 22000 sont autorisés. Et il insiste sur le fait que nombre d'entre eux ne respectent pas les distances de sécurité, soit 500 mètres d'écart avec les zones habitées, a fortiori pour les 85 \% d'Égyptiens pratiquant l'élevage domestique.

Le problème avec ce type de discours est qu'il réduit à un ensemble supposé homogène, le peuple égyptien, des pratiques, comportements et échelles très différents. II semble qu'en dernier recours, ce sont les petits éleveurs dont l'élevage de volaille est plus un moyen de subsistance qu'un moyen d'enrichissement, qui ont représenté aux yeux des représentants de l'État, la principale cause de la propagation de l'épidémie. Dans ce cadre, les responsables ont sans doute beau jeu de dénoncer I'" absence de prise de conscience des citoyens » (qillat wa'î al-muwâtinîn) et les Égyptiens mukhâlatîn, c'est-à-dire qui vivent en promiscuité avec les oiseaux.

L'apparition des cas humains est clairement reliée par le ministre de la Santé, Hâtim al-Gabalî, à la négligence des citoyens : "L'apparition de cas humains dévoile que l'abattage et l'enlèvement des oiseaux morts ou touchés ne se sont pas faits selon les "normes scientifiques" [uslûb 'ilmî] » (Nahdat Misr, 23 mars 2006). D'autres articles mettront en évidence la poursuite de vente de volaille vivante dans certains quartiers du Caire : "Grippe aviaire à vendre ». Le président du Syndicat des médecins en fait autant en rapportant I'apparition des cas humains aux pratiques de contrebande et d'inhumation

44. Entretien de Amîn Abâza, Al-Misrî al-Yawm, 20 février 2006. On comprend mal ce culturalisme mal placé de la part du ministre si ce n'est pour disposer ainsi d'une explication à peu de frais plaçant l'entière responsabilité sur les citoyens. La pratique de l'élevage domestique et des marchés d'oiseaux vivants est en effet commune dans les pays asiatiques (Chine, Viêt-Nam par exemple) pour lesquels les experts reconnaissent également la nécessité de mettre fin à la " préférence culturelle de manger des oiseaux fraîchement abattus », Wang et al., 2006. La question est plutôt celle-ci : comment l'ambition modernisatrice de l'industrie de la volaille, relancée par l'épizootie, crée-t-elle une tradition culturelle perçue dès lors comme néfaste? 
non scientifique (dafn ghayr al-'ilmî) et, plus largement, à la « résistance » (muqâwama) des individus aux opérations d'abattage.

Il y a eu de la part du gouvernement une ferme résolution de « moderniser » le secteur avicole et, profitant de l'épizootie, de mettre fin aux pratiques domestiques d'élevage et $d^{\prime}$ abattage ${ }^{45}$. Le projet de développer la commercialisation de viande de poulet congelée ou réfrigérée témoigne bien d'une ambition modernisatrice qui est en même temps une volonté de relégation de pratiques d'élevage dénoncées comme "traditionnelles».

Trois jours après l'annonce de la présence de la grippe aviaire en Égypte, Amîn Abâza accorde un entretien au quotidien indépendant Al-Misrî al-Yawm dans lequel il annonce la ferme résolution du gouvernement d'éliminer la pratique de l'élevage domestique : "C C'est terminé maintenant l'époque de l'égorgement dans les boutiques de rue et les maisons, et je pense que cette crise est une réelle occasion pour changer la culture [thaqâfa] de l'égorgement et de la vente de poulets en Égypte » (Al-Misrî al-Yawm, 20 février 2006). En guise de solution alternative, et pour pallier le manque de viande de poulet sur le marché égyptien, le ministre propose d'importer de la viande réfrigérée. L'état de crise est bien fait pour produire des figures de l'irréversibilité que le ministre instrumentalise allègrement : « À chaque début de siècle apparaît un type de bouleversement [hazza] qui change la culture en une autre. On peut l'accueillir d'un refus ferme jusqu'à ce qu'on s'y habitue. Mais même si on ne l'accepte pas, ce sera la seule solution devant nous. Nous n'allons plus permettre d'égorger hors des abattoirs » (Ibid.). L'introduction de volaille congelée dans l'alimentation des Égyptiens est devenue un des leitmotive de la politique de rupture et de réforme affichée par le gouvernement, les ministres s'engageant à faciliter l'achat de réfrigérateurs par les commerçants et les éleveurs. Le ministre de la Santé prêtera également sa voix pour encourager les Égyptiens à manger du poulet congelée ${ }^{46}$, qualifiant cette attitude de « comportement civilisé » (sulûk hadârî) (Al-Ahrâm, 9 avril 2006).

Des experts en nutrition sont venus s'exprimer dans les journaux, déplorant eux aussi des habitudes alimentaires "erronées » (khâti'a) et la culture de l'égorgement à domicile, en se félicitant que la grippe aviaire pourrait bien représenter un "préjudice bienfaisant » (dâra nâfi'a) pour changer cette culture $^{47}$. Le projet est soutenu par des hommes clés du parti Watanî, comme Ahmad 'Izz, responsable du personnel au sein du parti et homme d'affaires important (cité dans Afâq 'arabiyya, 2 mars 2006).

45. Sur le lien entre épizootie et modernisation agricole dans d'autres contextes, Ballard, 1986 ; Phoofolo, 1993 ; Beinart, 1997.

46. «Les oiseaux congelés sont bons pour la consommation», al-Jumuhûriyya, 2 mars 2006.

47. "Pourquoi les Égyptiens n'aiment-ils pas le poulet congelé ? , Rûz al-Yûsif Hebdo, 4/10 mars 2006. 


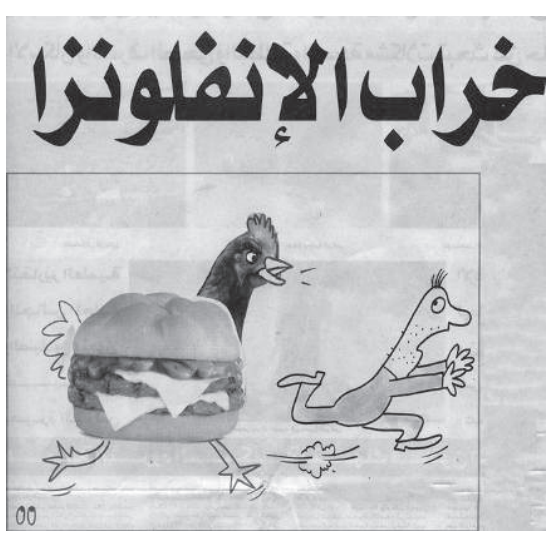

"Le saccage de la grippe »

Américanisation de la nourriture et menace grippale

Al-Karâma, 28 mars 2006

Le projet se heurte à cette « culture » populaire égyptienne soudainement dévalorisée avec la poursuite de l'élevage domestique. Les consommateurs rechignent à acheter le produit, des journaux pointent du doigt le caractère " mafieux » des importateurs de viande congelée $^{48}$. Les organisations d'éleveurs et de boutiquiers feront du refus de la viande réfrigérée un des motifs de leur mécontentement, les manifestants brandissant le slogan : "Non au réfrigéré ! " (al-mujammad la) (Al-Ahrâr, $1^{\text {er }}$ mars 2006). Cette défiance envers le projet modernisateur est assez bien rendue dans le dessin ci-contre assimilant la grippe aviaire et les « ajustements structurels » proposés à une américanisation de la nourriture.

\section{Amâl, femme et cachottière}

Par un curieux retournement de la situation, le statut des femmes va passer de celui de principales victimes (elles représentent la grande majorité des infections humaines et des décès) à celui de vecteurs de l'infection ${ }^{49}$. Le registre discursif se met en place dès l'annonce du décès d'Amâl, première victime humaine de la grippe aviaire en Égypte. Son transfert tardif à l'Hôpital des Poumons de 'Abbassiya au Caire, alors qu'elle avait passé plusieurs jours à I'Hôpital des Fièvres de Qalîubiyya, est expliqué en ces termes. Le diagnostic rapide aurait été empêché par le fait qu'elle niait élever de la volaille en dépit des décrets d'interdiction : "Amâl nous a trompés et elle a nié la maladie ", affirme par exemple le directeur de I'hôpital de 'Abbâsiyya (Nahdat Misr, 20 mars 2006). S'il n'est pas toujours simple de trouver une association étroite entre la victime et l'élevage domestique, les responsables trouvent toujours le moyen de se déculpabiliser, eux et leur administration, comme par exemple

48. "Les mafias du poulet congelé persistent à importer », Al-Wafd, 27 mars 2006.

49. On ne peut manquer ici de penser au cas célèbre de Mary Mallon, immigrée irlandaise arrivée aux États-Unis alors qu'elle était adolescente, cuisinière dans les familles bourgeoises de New York, et qui fut accusée d'avoir infecté vingt-deux personnes par la fièvre typhoïde entre 1900 et 1907. Les autorités de santé publique, aussi bien que les médias, firent de cette femme le portrait d'une menace pour la santé publique, d'une indésirable nécessitant l'internement à vie, Leavitt, 1996. 
pour la troisième victime, une dame venant également de Qalioubiya qui, si elle n'élevait pas elle-même d'oiseaux, aurait acheté un oiseau de contrebande (muharraba), et elle aurait mélangé son sang (ikhtalâtât) au sien en I'égorgeant (Nahdat Misr, 23 mars 2006).

Et il n'y a souvent qu'un pas à franchir pour rapporter l'endémisation de la grippe aviaire dans le pays au comportement malveillant des femmes. Le gouverneur de Qalîubiyya, 'Adlî Hussein, affirme ainsi que : « Les femmes ont caché les poulets sous les lits ${ }^{50}$. II réitère ses propos, encore plus explicitement, dans un entretien pour Uktûbar: "L'État n'est pas responsable de ce qu'ont causé ceux qui ont caché le poulet sous les lits »(Uktûbar, 9 avril 2006). La stigmatisation opérée par le gouvernement est ici largement partagée par la presse, qu'elle soit partisane ou gouvernementale comme à Rûz al-Yûsif : " Les femmes rurales [al-rîfiyyât] jettent les décrets gouvernementaux contre les murs et vendent les oiseaux sur le marché » (Rûz al-Yûsif, 27 mars 2006).

La guerre aux poulets a donc été aussi une guerre aux pauvres et, parmi eux, une guerre aux femmes. Là aussi, on peut parler d'une "guerre de civilisation " dans la mesure où ce sont les comportements alimentaires populaires qui ont été assimilés à des «erreurs » et voués à la disparition prochaine sous l'effet de l'épizootie et de la volonté modernisatrice du secteur avicole en Égypte.

\section{CONCLUSION}

Dans cet article, nous avons décrit la production symbolique des guerres de la grippe aviaire en Égypte d'une manière qui tient compte des temporalités de la crise, du maintien ou non de l'incertitude sur son origine et sa propagation, et de l'image que le gouvernement égyptien a voulu donner de son action. Nous avons montré, dans un premier temps, que la mobilisation d'images de la guerre était d'autant plus pertinente pour la presse que l'actualité égyptienne était dominée par les effets régionaux de la guerre contre le terrorisme. L'énoncé de la politique gouvernementale et sa réception dans la presse ont représenté un second moment. Nous y avons remarqué l'éclectisme des images de la guerre aux poulets, allant du diagnostic virologique jusqu'aux images plus nombreuses de l'abattage, du cordon sanitaire et de la surveillance policière. Dans un troisième temps, nous avons saisi la portée symbolique de la politique gouvernementale de destruction de l'élevage domestique et de promotion de l'élevage industriel. En assimilant les traditions populaires d'élevage domestique à un comportement "barbare », ils en ont en même temps stigmatisé les intercesseurs et, parmi eux, les femmes.

50. Al-Jumuhûriyya, 8 avril 2006. Le gouverneur lance également à cette occasion : "La grippe aviaire est en Égypte pour 10 ans » 
La guerre n'a donc pas été le seul registre métaphorique de la lutte contre la grippe aviaire en Égypte. Un second registre, au moins aussi présent, a été celui de la pollution au sens large, embrassant pollution environnementale et corruption morale et politique en passant par la pollution alimentaire. Largement utilisé par la presse, ce second registre a permis de lire l'épizootie comme une maladie du désordre et du déséquilibre sociaux. L'importance de ce registre est d'autant plus remarquable que son usage n'est pas cantonné au cercle restreint des prêcheurs musulmans qui n'ont pas hésité à voir dans la crise sanitaire une punition divine infligée à un peuple égyptien vivant dans le vice. À travers la dénonciation de "complots » (mu'âmarât), la mise à jour de "scandales » (fadîha) environnementaux et sanitaires impliquant des « mafias », la publicité donnée à certaines " rumeurs » (châ'i ât) et la stigmatisation de comportements frauduleux d'éleveurs ou de simples citoyens, la presse a donné l'image d'une société rongée par le parasitisme social de profiteurs. Dans ce cadre, la pollution environnementale et sanitaire représentée par l'épizootie est une conséquence directe de la pollution morale et politique des opérateurs, publics et privés, du secteur avicole. Si des nuances sont apportées en ce qui concerne le type de corruption morale et politique, ce trope de la corruption/pollution est partagé par l'ensemble des journaux. $\mathrm{Si}$, pour les titres de la presse gouvernementale, les profiteurs sont à chercher du côté de citoyens ou d'entrepreneurs individuels peu scrupuleux, la presse partisane et indépendante d'opposition s'est attachée à suggérer que les mafias avaient leurs bureaux dans les ministères d'un régime honni. Ce registre de la pollution, qui s'impose véritablement lors des déboires de la politique de vaccination vétérinaire dans les élevages industriels en avril 2006, suggère que l'analyse de la « crise » de la grippe aviaire en Égypte gagnerait à prendre en compte la dimension stratégique et instrumentale de l'activité de cadrage.

Tout en soulignant l'enjeu représenté par l'imposition d'une image de I'action gouvernementale, nous avons laissé dans l'ombre la dimension négociée des cadres de la crise sanitaire. Il reste en effet à démêler le travail émergent et contesté auquel se sont livrés les acteurs de la scène politique égyptienne reconfigurée après la première élection pluraliste du chef de l'État et l'entrée en force des Frères musulmans au Parlement en 2005. L'analyse de la manière dont les acteurs politiques (et, parmi eux, les journaux) se sont saisis de l'affaire permettrait de mieux situer l'épizootie dans le contexte politique égyptien. Davantage, elle fournirait des clés pour retracer les logiques d'institution de la crise de la grippe aviaire. Elle fournirait aussi une meilleure appréciation de la relation entre virus émergents, crise et état d'urgence que la description des métaphores de la guerre nous a seulement permis d'entrevoir. 


\section{RÉFÉRENCES BIBLIOGRAPHIQUES}

ANDERSON W., 2004, "Natural histories of infectious disease: ecological vision in twentieth-century biomedical science », Osiris, 19.

BALlaRD C., "The repercussions of rinderpest: cattle plague and peasant decline in colonial Natal», International Journal of African Historical Studies, 1986, 19(3), p. 421-50

Barrett R., Kuzawa C. W., McDade T. el Armelagos G., 1998, "Emerging and reemerging infectious diseases : the third epidemiologic transition », Annual Review of Anthropology, 27, p. 257-71.

Beinart W., "Vets, viruses and environmentalism at the Cape » dans Griffiths T. et RoBin L. (dirs), Ecology and empire. Environmental history of settlers societies, Seattle, University of Washington Press, 1997, p. 87-101.

Benford R. et SnOw D., 2000, "Framing processes and social movements : an overview and assessment », Annual Review of Sociology, 26, p. 611-639.

Carroll P. E., 2002, "Medical police and the history of public health ", Medical History, 46, p. 461-94

Cefaï D. et Trom D., 2001, Les Formes de I'action collective. Mobilisations dans les arènes publiques, Paris, Éd. de l'EHESS, "Raisons pratiques ».

Chevalier L., 2002 (1958), Classes laborieuses, classes dangereuses, Paris, Perrin.

CoOper M., 2006, "Pre-empting emergence. The biological turn in the war on terror », Theory, Culture and Society, 23(4), p. 113-125.

DaSilva E. et Iaccarino M., 1999, «Emerging diseases: a global threat», Biotechnology Advances, 17, p. 363-84.

Delaporte F., 1990, Le Savoir de la maladie. Essai sur le choléra de 1832 à Paris, Paris, PUF.

Derenne J.-P. et Bricaire F., 2005, Pandémie. La grande menace. Grippe aviaire 500000 morts en France, Paris, Fayard.

DOUGherTy S., 2001, "The biopolitics of the killer virus novel », Cultural Critique, 48, p. 1-29.

Evans R. J., 1988, "Epidemics and revolutions : cholera in nineteenth-century Europe », Past and Present, 120, p. 123-46.

FINTZ M., 2004-2005, "De l'éradication à la surveillance épidémiologique : les moustiques, l'Égypte et la santé publique internationale », Maghreb/ Machrek, 182, p. 111-124.

- 2006a, «Les métamorphoses du gouvernement du parasitisme en Afrique. Insecticides, frontières et civilisation dans la lutte antipaludique, 1930$1962 »$, Politix, 19(74), p. 149-71.

- 2006b, «A reform for the poor without them ? The fate of the Egyptian Health Programme Reform in 2005 »dans Kohstall F. (dir.), L'Égypte dans l'année 2005, Le Caire, Cedej, p. 227-56.

Gallagher N. E., 1990, Egypt's other wars : epidemics and the politics of public health, Syracuse, Syracuse University Press. 
Garrett L., 1994, The coming plague : newly emerging diseases in a world out of balance, New York, Penguin.

GiLman S., 1988, Disease and representation : images of illness from madness to AIDS, Ithaca, Cornell University Press.

Hall S., 1982, "The rediscovery of "ideology" : return of the repressed in media studies » dans Gurevitch M., Bennett T., Curran J., Woollacott J. (dirs), Culture, society and the media, Londres, Methuen.

HANSEN B., 2004, "New images of a new medicine: visual evidence for the widespread popularity of therapeutic discoveries in America after 1885 » dans Stapleton D. (dir.), Creating a tradition of biomedical research. Contributions to the history of the Rockefeller University, New York, Rockefeller University Press, p. 65-110.

Huntington S. P., 1996, The clash of civilizations and the remaking of world order, New York, Simon \& Schuster.

KING N. B., 2002, "Security, disease, commerce : ideologies of postcolonial global health », Social Studies of Science, 32(5-6), p. 763-89.

- 2004, "The scale politics of emerging diseases », Osiris, 19, p. 62-76.

Klaus E., 2006, "Le secret de polichinelle ou la constitution d'un public de scandale. À propos du changement de direction de la presse d'État » dans Kohstall F. (dir.), L'Égypte dans I'année 2005, Le Caire, Cedej, p. $175-202$.

LACHENAL G., 2005, "Les réseaux postcoloniaux de l'iniquité : pratiques et mises en scène de la recherche biomédicale au Cameroun », Outremers, 93, p. 123-49.

Lakoff G. et Johnson M., 1985, Les Métaphores dans la vie quotidienne, Paris, Éd. de Minuit, "Propositions».

Lamloum O., 2004, Al-Jazira, miroir rebelle et ambigu du monde arabe, Paris, La Découverte.

Latour B. et Woolgar S., 1996, La Vie de laboratoire. La production des faits scientifiques, Paris, La Découverte.

Latour B., 2001, "Sol amazonien et circulation de la référence » dans Latour B., L'Espoir de Pandore. Pour une version réaliste de l'activité scientifique, Paris, La Découverte, p. 33-82.

Leavitt J. W., Typhoid Mary. Captive to the Public Health, Boston, Beacon Press, 1996, p. 126-161

MAY R. M., 2005, "Infectious disease : can we avert a lethal flu pandemic ?», Current Biology, 15(22), p. R922-R924.

Mellor N., 2005, The making of arab news, Oxford, Rowman \& Littlefield.

Mendelsohn J. A., 1998, "From eradication to equilibrium : How epidemics became complex after WWI » dans Lawrence C. et Weisz G. (dirs), Greater than the parts. Holism in biomedicine, 1920-1950, New York/Oxford, Oxford University Press.

Mermier F. (dir.), 2003, Mondialisation et nouveaux médias dans l'espace arabe, Paris, Maisonneuve \& Larose. 
Mitchell T., 2002, Rule of Experts. Egypt, techno-politics, modernity, Berkeley, University of California Press.

Moulin A.M., 1991, Le Dernier langage de la médecine. Histoire de l'immunologie de Pasteur au Sida, Paris, PUF, coll. "Pratiques théoriques », p. 127-128.

- 2004, «L'éradication des maladies, remède à la globalisation ? d dans Michaud Y. (dir.), Qu'est-ce que la globalisation?, Paris, Odile Jacob, p. 207-228.

Nerlich B., 2004, "War on foot and mouth disease in the UK, 2001 : Towards a cultural understanding of agriculture », Agriculture and Human Values, 21, p. 15-25.

Phoofolo P., « Epidemics and revolutions : the rinderpest epidemic in late nineteenth-century Southern Africa », Past and Present, 1993, 138, p. 112-143

RaOult D., 2005, Les Nouveaux risques infectieux : SRAS, grippe aviaire, et après ? Paris, Éditions Lignes de Repères.

RosenberG C. E., 1979, "Towards an ecology of knowledge: on discipline, context and history ", dans Oleson A., Voss J. (dirs), The organization of knowledge in modern America, Baltimore, John Hopkins University Press, p. 440-55.

- 1992, «Framing disease : illness, society, and history » dans RosenBERG C.

E., Explaining epidemics and other studies in the history of medicine, Cambridge, Cambridge University Press, p. 307.

Snodgrass S. B., 2003, Bugchasers of Egypt, Xlibris Corporation.

SONTAG S., 1977, Illness as metaphors, New York, Farrar/Straus/Giroux.

- 1988, AIDS and its metaphors, Londres, Penguin.

Stapleton D., 2000, "The short-lived miracle of DDT », American Heritage of Invention and Technology, 15(3), p. 34-41.

TOMEs N., 1998, The gospel of germs: men women, and the microbe in American life, Cambridge, Harvard University Press,

TOMEs N., 2002, "Epidemic entertainments : disease and popular culture in early-twentieth-century America », American Literary History, p. 625-52.

UnGAR S., 1998, "Hot crises and media reassurance : a comparison of emerging diseases and Ebola Zaire », British Journal of Sociology, 49(1), p. 36-56.

Waluis P.et Nerlich B., 2005, "Disease metaphors in new epidemics : the UK media framing of the 2003 SARS epidemic », Social Science and Medicine, 60(11), p. 2629-2639.

WANG M. et al., "Food markets with live birds as source of avian influenza », Emerging Infectious Diseases, 2006, 12(11), p. 1773-1775.

Weinding P. J., 2000, Epidemics and genocide in Eastern Europe, 1890-1945, Oxford, Oxford University Press. 